\title{
The Phylogenetic Distribution of Electroreception: Evidence for Convergent Evolution of a Primitive Vertebrate Sense Modality
}

\author{
T. H. BULLOCK'1, D. A. BODZNICK² and R. G. NORTHCUTT ${ }^{3}$
}

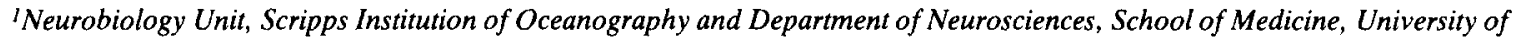
California, San Diego, La Jolla, CA 92093, '2Department of Biology, Wesleyan University, Middletown, CT 06457 and ${ }^{3}$ Division of Biological Sciences, University of Michigan, Ann Arbor, MI 48109 (U.S.A.)

(Accepted January 25th, 1983)

Key words: electroreception — phylogenetic distribution — vertebrate — ampullary organ — tuberous organ - sense modality convergent evolution

\section{CONTENTS}

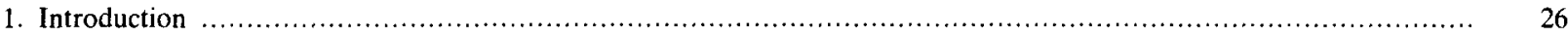

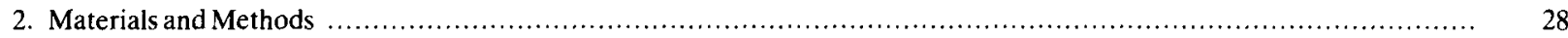

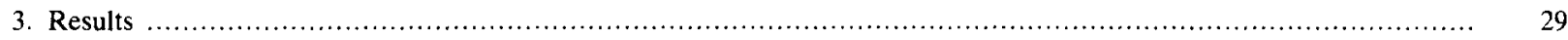

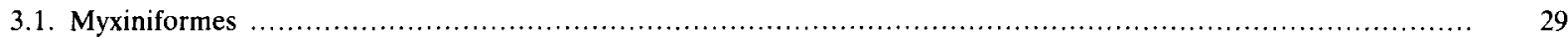

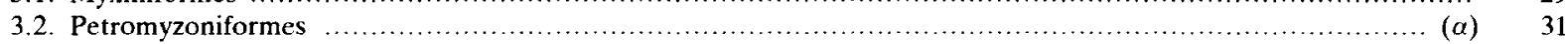

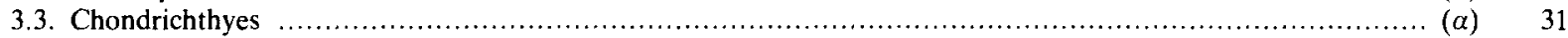

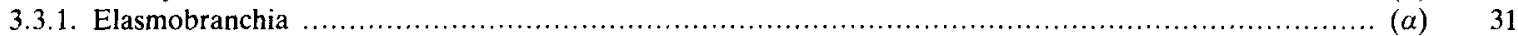

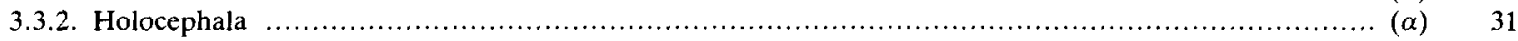

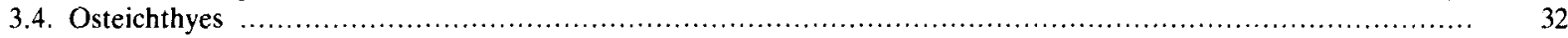

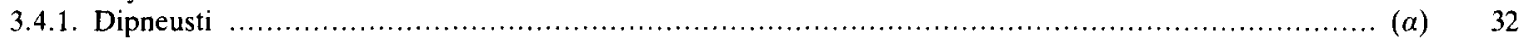

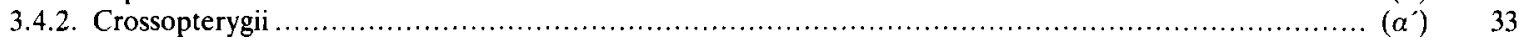

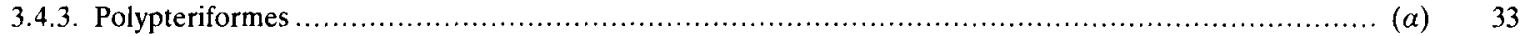

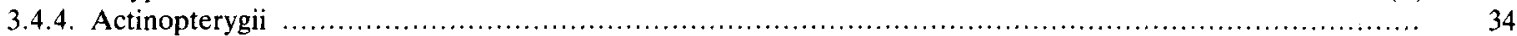

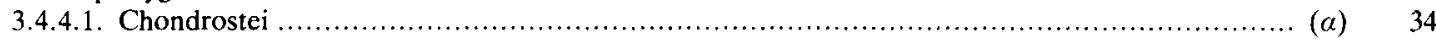

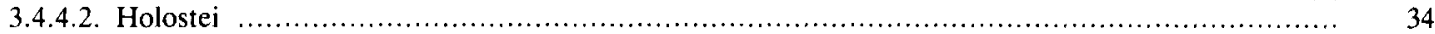

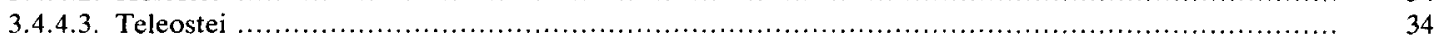

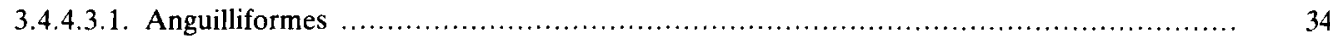

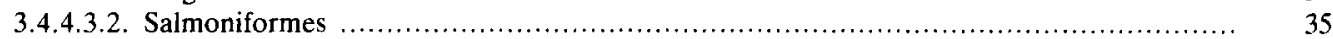

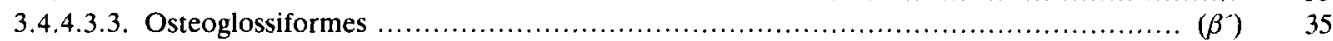

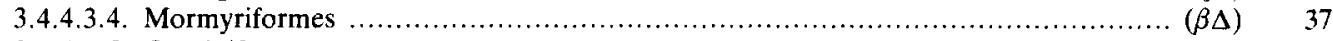

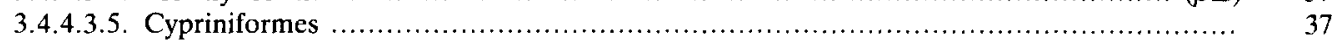

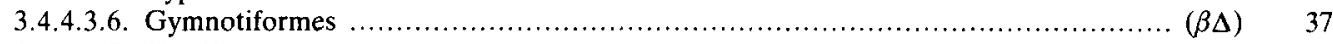

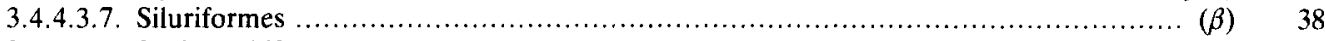

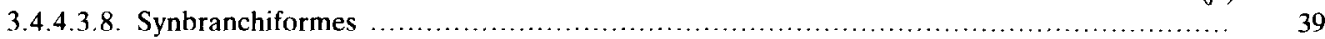

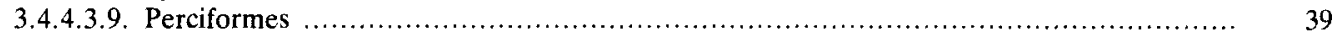

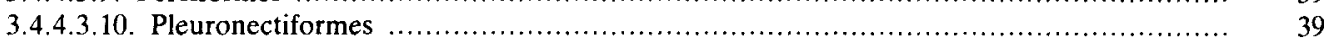

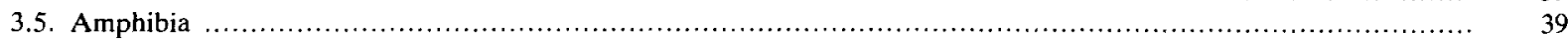

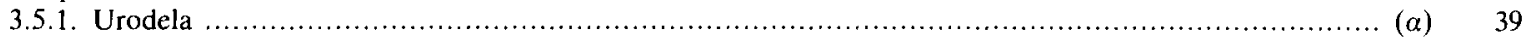

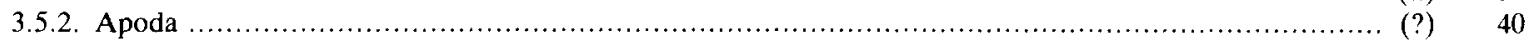

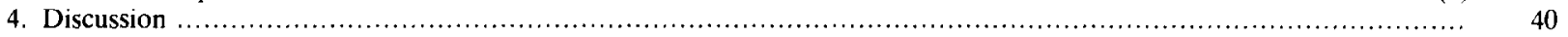

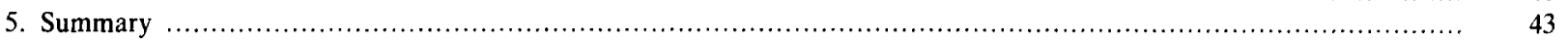

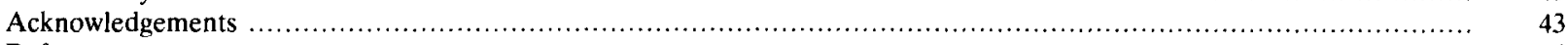

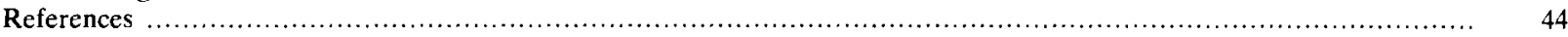

$\alpha=$ electroreceptive, with ampullary sense organs usually identified as Lorenzinian, and with electrosensory dorsal nucleus of octavolateral lobe of medulla (DN).

$\alpha^{\prime}=$ electroreception inferred from presence of DN.

$\beta=$ electroreceptive, with ampullary sense organs of teleost type, and with electroreceptive lateral line lobe (ELLL).

$\beta^{\prime}=$ one subfamily is electroreceptive, with ELLL; sense organs unknown.

$\Delta=$ with additional class of tuberous sense organs. 


\section{INTRODUCTION}

Electroreception is now known in many taxa of fishes and amphibians, but not in other vertebrates or in any invertebrates $21,27,85$. The evolution of electroreception in vertebrates may be of general interest because it is quite different from that of many other sense modalities including mechanoreception by the lateral line, the most closely related sensory system. Electroreception appears to have been lost, not merely in single families or lower taxa, but in the common ancestors of Holostei and Teleostei and may have been repeatedly ( $2-4$ times) and independently invented in several teleost radiations by the development of novel receptors in the periphery and of nuclei in the central nervous system out of the common clay of the peripheral and central lateral line system. This paper combines new data and a review of the literature to arrive at a general account of the probable evolution.

By way of definition, electroreceptive animals have at least one set of sense organs specialized for the detection and measurement of feeble, naturally occurring electric fields in the ambient medium, plus specialized brain structures that process this information and influence responses appropriate to the stimulus. The sensitivity to electric fields, best given as volts per centimeter in the water at the position of the animal (the effective stimulus is probably the voltage between the outer side and the body fluid side of the receptor cell), is typically highest for behavioral endpoints, lowest for single receptor responses and intermediate for brain responses. Behavioral thresholds vary from $0.005 \mu \mathrm{V} / \mathrm{cm}$ for a conditioned response in marine elasmobranchs up to $0.5 \mu \mathrm{V} / \mathrm{cm}$ or higher for the jamming avoidance response of freshwater electric fish. Receptor thresholds range from $<1$ $\mu \mathrm{V} / \mathrm{cm}$ in the marine ray to values $<10 \mu \mathrm{V} / \mathrm{cm}$ in non-electric freshwater fish, $<100 \mu \mathrm{V} / \mathrm{cm}$ in lowfrequency sensitive receptors of freshwater electric fish up to as high as $2 \mathrm{mV} / \mathrm{cm}$ for those of electric fish which are specialized to monitor the fish's own electric organ discharge. Table I summarizes the known varieties of electroreceptors and their brain centers.

Up till now it has not been clear just which groups of animals have sufficient specialization in respect to detection and analysis of naturally occurring electric fields to be regarded as electroreceptive. Such a list is essential if we are to understand the evolution of this sense modality. It has not been clear hitherto whether such a list is possible or whether some or many taxa are transitional or have a poorly developed electric sense. Recently accumulated evidence suggests that groups of this transitional type are uncommon and that a fairly good list is now possible.

The well-known electroreceptive groups are 4: (a) the Elasmobranchia, (b) Siluriformes, (c) Gymnotiformes, and (d) Mormyriformes ${ }^{21}$. Other known electroreceptive groups are less familiar, but convincing reports have been published for representative species of (e) lungfish (Dipneusti) and (f) Polypterus (Polypteriformes, formerly Brachiopterygii ${ }^{102}$, for (g) the paddlefish, Polyodon ${ }^{10}$ and sturgeon, Scaphirhynchus (Chondrostei) ${ }^{57,112}$. Northcutt ${ }^{91}$ gave reasons from brain anatomy to believe electroreception is present in (h) Latimeria (Crossopterygii). Bodznick and Northcutt ${ }^{16}$ demonstrated this sensory modality physiologically in (i) lampreys (Petromyzoniformes). In a single subfamily, (j) Xenomystinae of the African knife fishes (Osteoglossiformes), though not in the closely related subfamily Notopterinae or in other families, both anatomical evidence and physiological demonstration of electroreception have recently been found ${ }^{18,26}$. (k) Some aquatic Urodela, including Salamandra (Salamandroidea) and the axolotl Ambystoma (Ambystomatoidea) have also been found recently to have the specialized sensitivity and corresponding sense organs and brain nucleus $^{40-43,54,85}$. (1) A suggestion that electroreception may occur in some caecilian amphibians (Apoda) ${ }^{31.36}$ appears to be supported by histological evidence from larval ichthyophids ${ }^{53}$.

Claims have been published for the eel, Anguil$l a^{77,100,101}$ and denicd ${ }^{13,35}$. A similar unconfirmed claim has been made for the salmon, Salmo ${ }^{77,101}$. The absence of electroreception in most fishes has been implied from the absence of behavioral evidence and of histological descriptions of relevant receptors. Virtually no direct tests of electrical responsiveness (apart from the relatively high thresholds for galvanotaxis ${ }^{60}$ ) appear to have been reported for other taxa than those mentioned above, including other vertebrates and invertebrates.

Besides being incomplete the nature of the evidence is unsatisfactory. Histological evidence of the absence of relevant receptors in the skin is particular- 
TABLE I

Summary of the varieties of electroreceptors and their brain centers

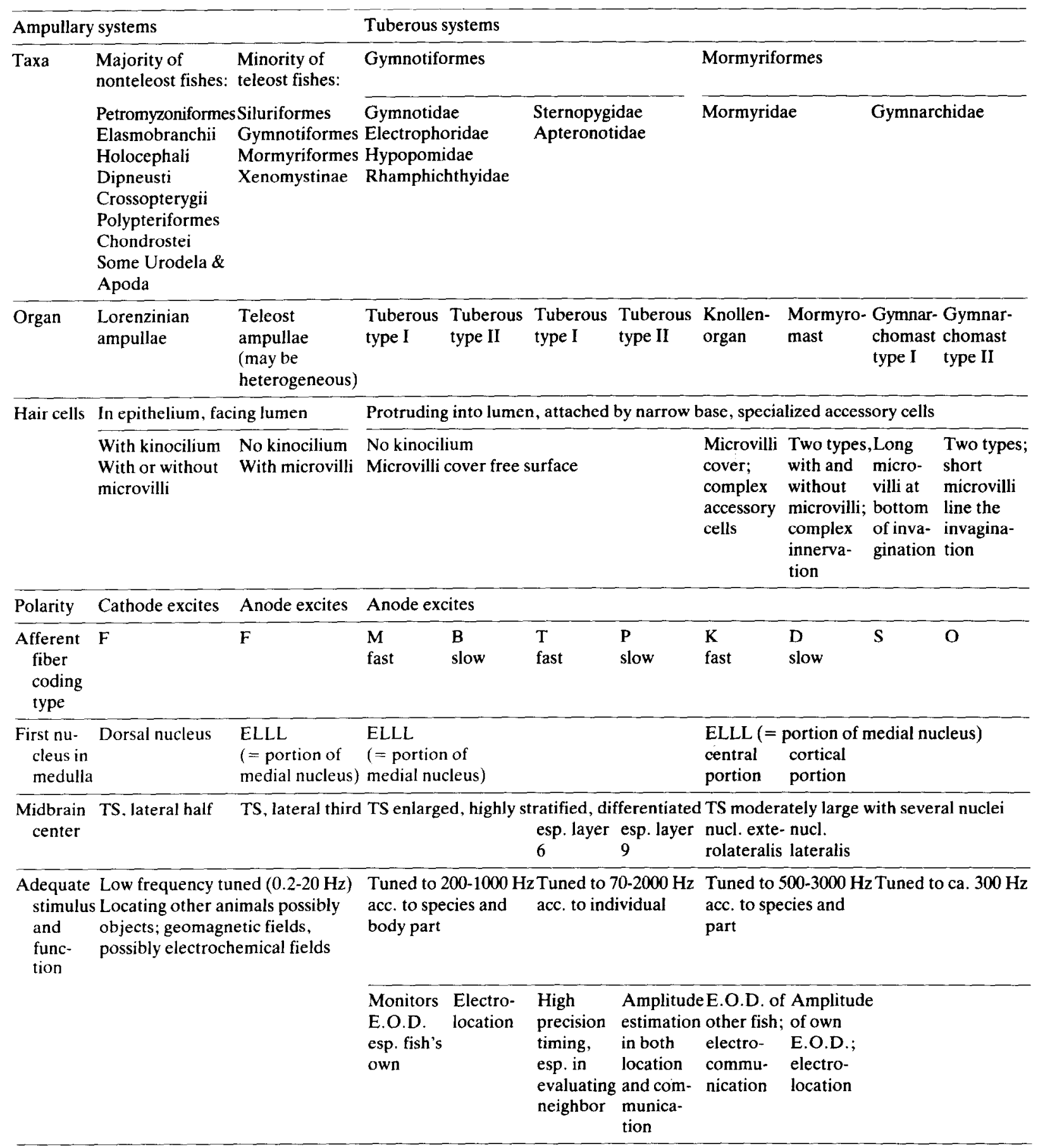

Modified from Bullock et al.27. TS, torus semicircularis; ELLL, electroreceptive lateral line lobe. 
ly insecure since, apart from sampling error, we cannot be confident that the organs must everywhere look like those identified in the best studied taxa. This is all the more true in view of the reasonable presumption that electroreception, like electric organs, evolved independently several times ${ }^{6-10} 20.21,25,68.79$.

For purposes of surveying many species of diverse groups behavioral tests as well as single receptor recording techniques are very time consuming. One purpose of this paper is to apply to many taxa of fishes the method of recording evoked potentials as a direct test of responsiveness to feeble electric fields including some taxa hitherto not tested and some claimed to be electroreceptive by other methods. The evoked potential method, as used here, depends on averaging the responses to repeated stimuli recorded by semimicroelectrodes placed in relevant structures in the medulla or midbrain. As we will show, these direct methods that demonstrate electroreception physiologically have now validated some new diagnostic criteria in brain anatomy. Criteria based on skin histology are suggestive but not as secure in deciding whether a species can be listed as electroreceptive.

Another purpose of this paper therefore is to apply the method of comparative brain anatomy to this problem. Studies by McCready and Boord 82 and Bodznick and Northcutt ${ }^{15}$ have shown that the dorsal nucleus of the octavolateral lobe of the medulla in elasmobranchs receives all the ampullary (electroreceptive) afferents and only ampullary afferents. The histological demonstration of a dorsal nucleus (DN) will be shown in the present survey to correlate consistently with the physiological demonstration of electroreception, and thus to become itself a reliable test in non-teleost fishes for the presence of this sense modality, as expected by McCready and Boord 82 and McCormick ${ }^{79} 81$.

The dorsal nucleus is not found in teleosts, even those that are known to be electroreceptive. These fishes receive electroreceptor afferents in a special portion of their medial nucleus, formerly called the posterior lateral line lobe by some authors ${ }^{72.75}$, now generally called the electroreceptive lateral line lobe, ELLL. It is not yet established as firmly as for the DN of nonteleosts that the FI.I.I. is present, distinctive and equivalent in all electroreceptive teleosts and is not present in any which are physiologically without specialized electroreception. It would be useful to establish this, by correlating physiological and anatomical findings in additional orders of teleosts, since the anatomy might prove to be the most convenient diagnostic test for this sense modality in the large number of teleost orders and families not yet examined, and thus aid in uncovering further the evolutionary story which is the overall objective of this paper.

A brief statement of the conclusions here supported has been published ${ }^{27}$.

\section{MATERIALS AND METHODS}

Table II lists the species studied and whether they were examined physiologically or anatomically. The animals were obtained from collectors and commercial importers and were maintained and tested in seawater or fresh water (resistivity, $9 \times 10^{3} \Omega \mathrm{cm}$ ) at a temperature near that of the animal's natural environment.

The fish were first anesthetized by immersion in $0.01 \%$ tricaine methanesulfonate (MS222) and then injected with the muscle relaxant D-tubocurarine chloride (normally $1-5 \mathrm{mg} / \mathrm{kg}$, intramuscularly or intravenously) or Flaxedil ( $4 \pm \mathrm{mg} / \mathrm{kg}$, intramuscularly). The overlying tissue and roof of the cranium were removed to expose the dorsal aspect of the brain. The fish were fixed in a shallow plastic experimental tank with the aid of a head clamp. The gills were ventilated with oxygenated water without MS222. The condition of the fish was monitored by watching the blood flow through vessels on the surface of the brain, as well as the light flash evoked potential from the tectum and, in some cases, the electrocardiogram.

Stimuli from $0.01 \mu \mathrm{V} / \mathrm{cm}$ to $100 \mathrm{mV} / \mathrm{cm}$ as square pulses from $<5$ to $>100 \mathrm{~ms}$ long, or sinusoidal currents were delivered between long carbon rod electrodes delivering virtually uniform fields. Stimulus intensity was monitored with a pair of $\mathrm{Ag}-\mathrm{AgCl}$ electrodes positioned in the field. In some cases sensitivity to local electric fields was tested using a handheld $\mathrm{Ag}-\mathrm{AgCl}$ roving stimulating electrode with one of the carbon rods as a remote reference electrode. A $10^{5}-10^{6} \Omega$ resistor was normally placed in series with the carbon electrodes to assure constant current and minimize the influence of currents due to electrode 
TABLE II

Species examined $\left(^{*}=\right.$ physiologically $;{ }^{+}=$anatomically $)$

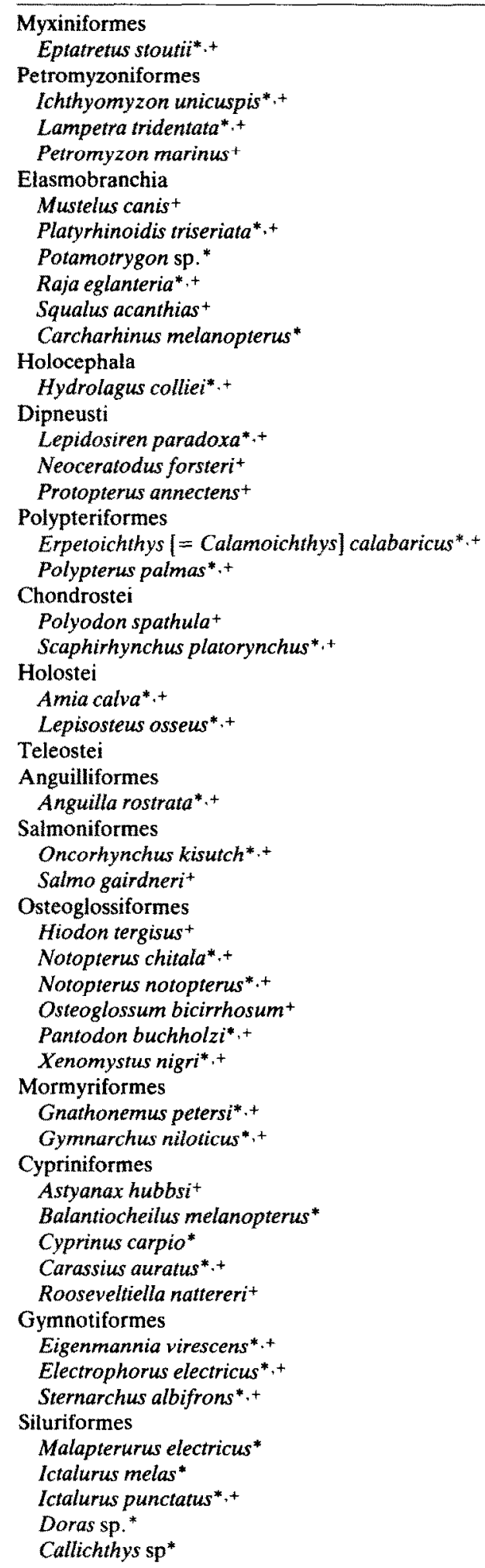

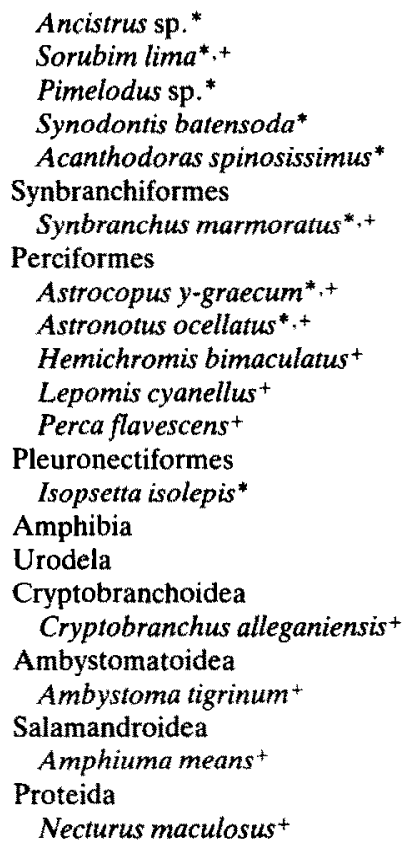

Terminology for most taxa follows Nelson ${ }^{89}$; for gymnotiforms we follow Mago-Leccia ${ }^{70}$.

polarization.

Evoked potentials, 'hash' potentials (spikes smaller or barely larger than background noise level) multiple unit and occasional single unit responses were recorded with glass micropipettes $(5-10 \mu \mathrm{m}$ tip diameter) or low resistance stainless steel or tungsten microelectrodes $(1-10 \mathrm{M} \Omega)$. Signals were amplified with high and low pass filters at $3 \mathrm{~Hz}$ or lower, and 1 $\mathrm{kHz}$ or higher for evoked potentials, $30 \mathrm{~Hz}$ and $3 \mathrm{kHz}$ for spikes. A computer was used to improve the signal to noise ratio of evoked potential records by averaging, and to generate post-stimulus time histograms of unit spikes. In many cases recording sites were marked for histological identification using the Prussian Blue technique ${ }^{44}$ or electrolytic lesions.

Brains of the species listed in Table II were embedded in paraffin following transcardial perfusion, cut in transverse serial sections $(15 \mu \mathrm{m})$, and stained with cresyl violet for examination of the medullary nuclei.

\section{RESULTS}

\subsection{Myxiniformes}

The jawless vertebrates are best separated into 
two major taxa, embracing the hagfish, the subject of this section, and the lampreys, treated in the next section. According to recent views these are only distantly related. Our sample of the hagfish group is $E p$ tatretus stouti, from 100-200 m depth off La Jolla.

Electrophysiologically, we have found no evoked potentials to electric fields up to $400 \mu \mathrm{V} / \mathrm{cm}$, the maximum tested, in many electrode tracks through the midbrain and the medulla of 7 specimens. This intensity does not seem high but good evoked potentials in sharks are recorded with much less than $1 / 1000$ of this intensity and in other marine forms with less than $1 / 100$. We used both homogeneous field and local monopole stimulation applied by an electrode that explored various parts of the body surface. Pulses usually of $10 \mathrm{~ms}$ but up to $100 \mathrm{~ms}$ were applied, typ-

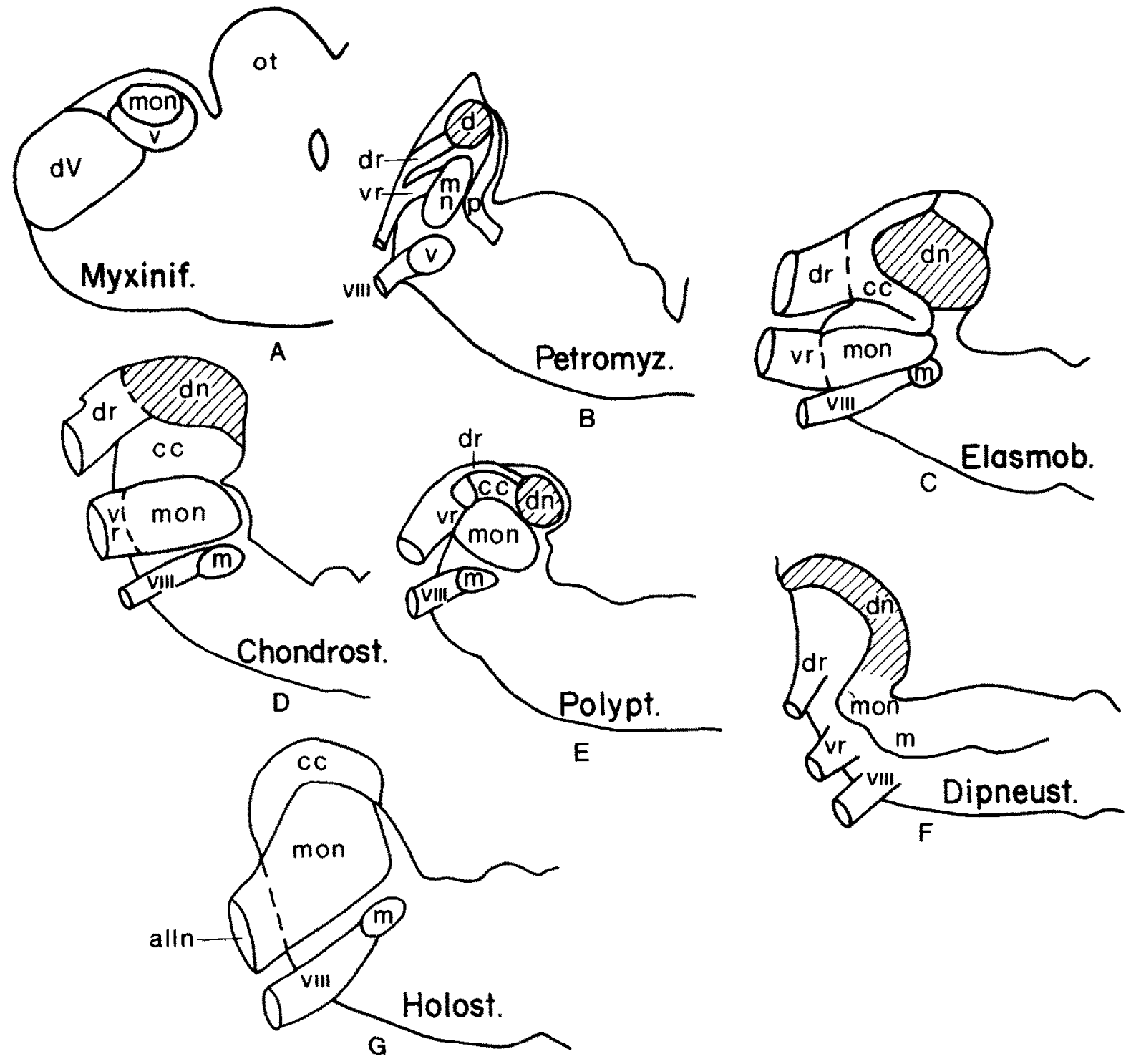

Fig. 1. Variation in the octavolateralis area of the medulla in non-teleost fishes seen in diagrammatic transverse sections of one side of the medulla. Drawings are not to the same scale. Shaded areas, dorsal nucleus, the first relay for electroreception. A: Eptatretus. B: Petromyzon. C: Platyrhinoidis. D: Scaphirhynchus. E: Erpetoichthys. F: Lepidosiren. G: Amia. Abbreviations: alln, anterior lateral line nerve; $c c$, cerebellar crest; $d$, neuropile of dorsal octavolateral nucleus; dn, dorsal octavolateral nucleus; dr, dorsal root of alln; $\mathrm{dV}$, nucleus and descending trigeminal tract; $\mathrm{m}$, magnocellular octaval nucleus; $\mathrm{mn}$, neuropile of medial octavolateral nucleus; mon, medial octavolateral nucleus; ot, optic tectum; $p$, cell plate of octavolateral area; $v$, ventral octavolateral nucleus; vr, ventral root of alln; VIII, octaval nerve. 
ically at one per second, and the brain potentials following 64-256 such stimuli were averaged at high gain. Evidence that the preparation was alive and responsive could be observed both in small flashevoked potentials in the midbrain and in touchevoked responses of units in the midbrain as well as peripherally in the branches of the trigeminal nerve that cross the subcutaneous lymph space. The absence of electric evoked potentials is not completely convincing, in that a small number of responsive cells could have been missed. Nevertheless, in view of the consistent correlation of evoked potentials with other evidence of electroreception or its absence in many species, the negative findings here represent at least a strong indication. These animals are probably not electroreceptive; if they are, the threshold is very high or/and they have few responsive units.

Anatomically, the lateralis area is poorly differentiated in hagfishes, compared to other vertebrates, and consists of a column of cells occupying the dorsomedial horn of the rostral medulla (Fig. 1A). In Eptatretus, an anterior lateral line nerve and an octaval nerve enter the lateral edge of the octavolateralis area, but a distinct posterior lateral line nerve cannot be recognized. The anterior lateral line nerve is not divided into dorsal and ventral roots, as in lampreys and primitive jawed fishes, nor do dorsal and ventral octavolateral nuclei appear to exist. All of these data suggest that the lateralis system in hagfishes is solely mechanoreceptive and restricted to the head.

\subsection{Petromyzoniformes}

The findings in this part of the project have been published separately ${ }^{16}$ and will not be repeated in detail here. Lampreys (Lampetra tridentata) were found to have electroreception, with high sensitivity (thresholds to the most favorable oricntation and polarity as low as $0.1 \mu \mathrm{V} / \mathrm{cm}$, equivalent to $10^{-5}$ $\mu \mathrm{A} \cdot \mathrm{cm}^{2}$ ). Single unit spike responses as well as slower evoked potentials were recorded. The locus of earliest responses was in the dorsal nucleus of the octavolateral area of the medulla. In the midbrain responses of progressively longer latency were found deep to the tectum, in a region representing the lamprey torus semicircularis, and in the tectum itself. All latencies were much longer than in elasmobranchs, perhaps as a result of the absence of myelin.
Anatomically the lateralis column of the medulla in lampreys consists of distinct dorsal and medial nuclei (Fig. 1B). The dorsal octavolateralis nucleus (DN) begins immediately caudal to the cerebellum and ends slightly caudal to the entry of the anterior lateral line nerve. The medial octavolateralis nucleus is continuous with the cerebellum rostrally and ends just rostral to the obex of the medulla. The anterior lateral line nerve is characterized by dorsal and ventral roots, which enter the dorsal and medial octavolateralis nuclei, respectively. The posterior lateral line nerve enters only the medial nucleus.

\subsection{Chondrichthyes}

\subsubsection{Elasmobranchia}

Evoked potentials have confirmed and extended the earlier evidence of electroreception from behavior and peripheral nerve recording $20,22,24,30,33,34,58-60,86-88,93$. Platt et al. ${ }^{98}$ recorded from the brain in the rays Torpedo, Raja, Myliobatis, and the shark Scylliorhinus.

In this group we have the most information, for example the response to various sinusoidal frequencies of current in the water and the evoked potential in various levels of the brain: medulla, midbrain, cerebellum ${ }^{114}$ and telencephalon (Fig. 2), but not yet from the diencephalon.

Anatomically, elasmobranchs show a lateralis column divided into dorsal and medial octavolateralis nuclei (Fig. 1C) and the anterior lateral line nerve is characterized by dorsal and ventral roots ${ }^{15,82}$, as in lampreys and holocephalans. The DN appears to receive all the ampullary, that is to say all the electroreceptive input and no other primary afferents.

\subsubsection{Holocephala}

Following the discovery of peripheral electric sense organs in ratfish (chimaeras) by Fields and Lange ${ }^{39}$ who recorded from units in the lateral line nerves, we applied the evoked potential technique to the brain ${ }^{23,27}$. The results (Fig. 2) are closely similar to those found in elasmobranchs.

Anatomically, holocephalans show a lateralis column which consists of dorsal and medial octavolateralis nuclei and the anterior lateral line nerve has dorsal and ventral roots. The physiologically demonstrated electroreceptive $\mathrm{DN}^{23}$ is a conspicuous struc- 

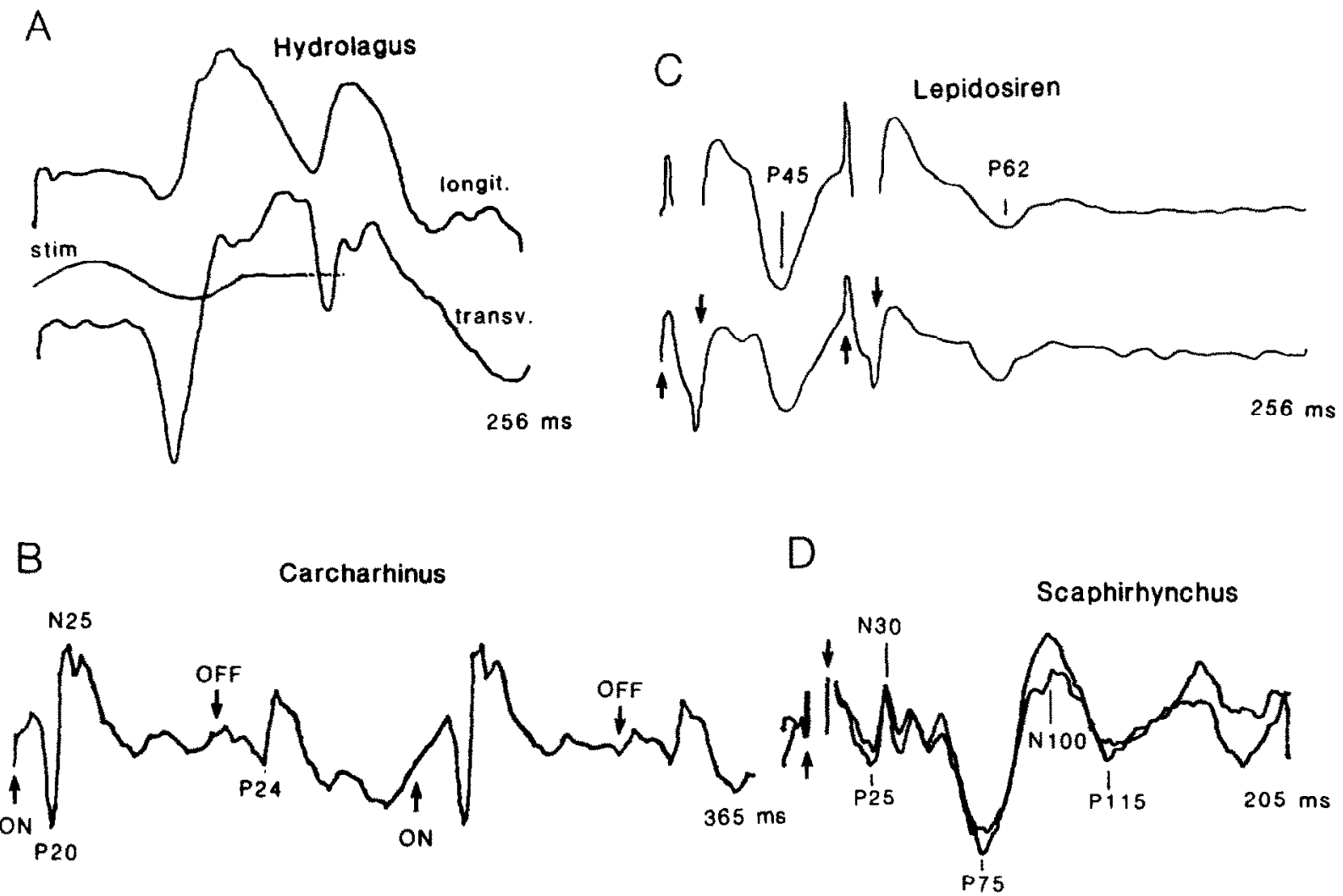

Fig. 2. Examples of electric field evoked potentials and some of their properties in non-teleost fishes. Negativity of the brain electrode, downwards; wave peaks designated by polarity and latency in ms. A: Holocephala, Hydrolagus colliei, ratfish, vicinity of dorsal nucleus; response to uniform field, single cycle of sine wave equivalent to $10 \mathrm{~Hz}, 8 \mu \mathrm{V} / \mathrm{cm}$, longitudinally with tail initially positive going. Transverse with ipsilateral side initially positive going. Average of 16 sweeps. B: Elasmobranchia, Carcharhinus melanopterus blacktipped reef shark, vicinity of dorsal nucleus, response to $100 \mathrm{~ms}$ pulses with $100 \mathrm{~ms}$ intervals, $2.4 \mu \mathrm{V} / \mathrm{cm}$, longitudinal. Average of 64 sweeps. C: Dipneusti, Lepidosiren sp., lungfish, vicinity of eminentia granularis; response to pairs of $10 \mathrm{~ms}$ pulses, longitudinal, tail positive with $70 \mathrm{~ms}$ between pulses in each pair; upper trace at $400 \mu \mathrm{V} / \mathrm{cm}$; lower at $200 \mu \mathrm{V} / \mathrm{cm}$. Note that recovery of responsc at this interval is incomplete in amplitude and delayed. Average of 16 sweeps. At lower intensity waves N32, N68, P75 and P95 emerge. D: Chondrostei, Scaphirhynchus platorynchus, sturgeon; vicinity of torus semicircularis; responses to $10 \mathrm{~ms}$ pulses, $250 \mu \mathrm{V} / \mathrm{cm}$ contralateral side positive; note that a strong stimulus evokes a series of waves.

ture, much like that in elasmobranchs.

\subsection{Osteichthyes}

\subsubsection{Dipneusti}

Roth ${ }^{102}$ reported sensitivity of the lungfish, Lepidosiren paradoxa to weak electric fields, by behavioral response after conditioning and by recording single fiber activity from the afferent nerve elicited by $\mathrm{DC}$ current steps. Spontaneous firing was increased by making the electrode near the skin cathodal - as for ampullae of Lorenzini elsewhere. Roth gives the stimulus in current density, $0.3 \mu \mathrm{A} \cdot \mathrm{cm}^{2}$. Depending on the conductivity of the fresh water used, this might have been a voltage gradient of perhaps $0.3-6 \mathrm{mV} / \mathrm{cm}$ at the opening of the plastic tube carrying the current, i.e, not very weak.

We have recorded the evoked potentials from Lepidosiren using $10 \mathrm{~ms}$ uniform field pulses. The best loci encountered in 11 tracks in 3 animals, were in the anterolateral medulla, in the region of the dorsal octavolateralis nucleus, and under the optic tectum in the torus semicircularis. In the medulla (Fig. 2) a positive peak at $45 \mathrm{~ms}(\mathrm{P} 45)$ became very large at near-maximal stimulus intensity, which was 400 $\mu \mathrm{V} / \mathrm{cm}$

The evoked potential method permits analysis of the dynamics of response. At the medullary locus de- 
scribed, a second stimulus pulse has to be more than $200 \mathrm{~ms}$ after the first to elicit a fully recovered response. However, in a train of stimuli at $140 \mathrm{~ms}$ intervals, the third and fourth responses are larger than the second and this is even more true in a train at 35 ms intervals where the facilitation from the small second response continues to grow for at least the next 5 responses. Recovery of P50 is more rapid for weak stimuli. A given locus is quite specific to the axis and polarity of the electric field and different loci can be quite different in their orientation preference.

Anatomically, the lungfish lateralis column and anterior lateral line nerve (Fig. 1E) are characterized by the same organizational pattern as in elasmobranchs (see below).

\subsubsection{Crossopterygii}

Northcut ${ }^{91}$ described a dorsal nucleus in Latimeria. He concluded that this animal is electroreceptive, based on the evidence reviewed here, from electrophysiological and anatomical studies of other taxa, that the dorsal nucleus receives only electroreceptive input.

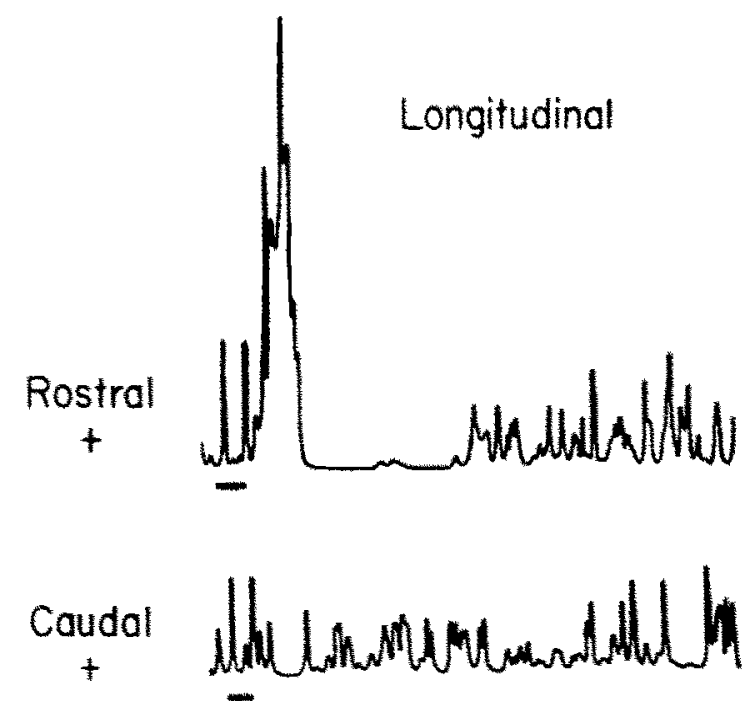

\subsubsection{Polypteriformes}

Roth $^{102}$ reported the sensitivity of Erpetoichthys calabaricus (then called Calamoichthys) to a 0.3 $\mu \mathrm{A} \cdot \mathrm{cm}^{2}$ current, by a learned avoidance movement and by impulses recorded from the skin surface directly over certain spots on the head, identified histologically as corresponding to the ampullary-like organs of Fahrenholz.

Evoked potentials are readily recorded in both $E$. calabaricus and Polypterus palmas from medullary and deep midbrain loci. The most sensitive locus we have encountered in 13 tracks explored in 4 animals was in the region of the octavolateral lobe of the medulla; here responses could be seen down to $1 \mu \mathrm{V} / \mathrm{cm}$ or less, with moderate averaging. Each locus is specific for a certain axis and polarity of homogeneous field stimulation (Fig. 3). Lesions at the sites where spikey hash was found showed the midbrain locus to be in the torus semicircularis, the medullary one to be in the dorsal nucleus. The main evoked wave in the torus is $\mathrm{N} 50$,

The lateralis column and anterior lateral line nerve of polypteriform fishes (Fig. 1F) are characterized by

\section{Transverse}
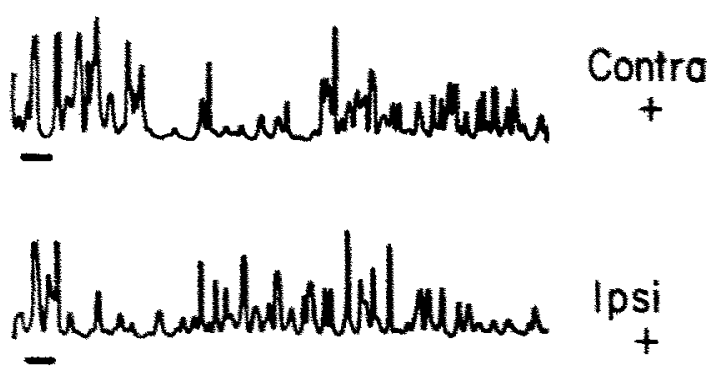

Fig. 3. Polypterts. Histograms of unit spike activity recorded from the medulfa in response to uniform 10 ms electric field pulses of $<$ 50 V Vicm, in the designated axes and poiarities. The timing of the stimulus pulses is shown by the bars below the histograms. The ordinate is a linear measure of spikes per unit time. The most excitatory stimulus is also the most inhibitory, but the preferred axis and polarity are specific to this locus and not necessarily the same for other loci in the nucleus. 
the same organizational pattern as in chondrosteans $\mathbf{s}^{67.80}$.

\subsubsection{Actinopterygii}

3.4.4.1. Chondrostei. Jørgensen et al. ${ }^{57}$ found ampullary sense organs histologically in the paddlefish, Polyodon. Kalmijn ${ }^{6(1)}$ reported preliminary behavioral evidence of electroreception in this fresh-water filter feeder. Teeter et al. ${ }^{112}$ described ampullary organs microscopically and physiologically in the sturgeon, Scaphirhynchus, concluding that they are electroreceptors and should be classified as ampullae of Lorenzini homologous to elasmobranch rather than teleost lines.

We have followed the ampullary input into the brain in Scaphirhynchus platorynchus by recording responses to weak electric fields in the water. Good responses in the form of smooth evoked potentials and in more restricted loci spikey hash are found under the tectum, in the position of the torus semicircularis, and in the dorsal nucleus of the medulla. The sign and latency of the waves depend on intensity, direction and polarity of the electric field as well as the locus of recording. For example in a certain locus in the torus semicircularis a $50 \mu \mathrm{V} / \mathrm{cm}$ field in the optimal axis and polarity, caused a succession of waves, the largest being P75. A strong stimulus, $250 \mu \mathrm{V} / \mathrm{cm}$ added 3 earlier and several later peaks: P25, N30, N50, N60, N100, P115 (Fig. 2D). For comparison, single ampullary afferent fibers are reported by Teeter et al. ${ }^{112}$ to show a threshold change in spontaneous firing to a few tenths of a millivolt with a cathode brought to a critical position close to the skin.

Anatomically, the lateralis column in paddlefishes and sturgeons consists of well-developed dorsal and medial octavolateralis nuclei (Fig. 1D). Both nuclei are capped rostrally by granule cells that are probably homologous to the eminentia granularis of elasmobranchs. The anterior lateral line nerve consists of dorsal and ventral roots which enter the dorsal and medial octavolateralis nuclei, respectively $67,80,90$

\subsubsection{Holostei. McCormick ${ }^{78}$ found that Amia} and Lepisosteus lack a dorsal nucleus - making these the only non-teleost fishes besides hagfish that lack this nucleus, identified with electroreception.

Our electrophysiological tests have confirmed the expectation that holosteans lack electroreception. In 22 electrode tracks in 5 Amia calva, in midbrain and medulla, we concentrated on those areas most likely to show electric evoked potentials in other taxa. Either no such response was found, using stimuli up to $>10 \mathrm{mV} / \mathrm{cm}$, or just perceptible responses could be obtained by averaging with stimuli of about 200 $\mathrm{mV} / \mathrm{cm}$. Such a high intensity might excite unspecialized lateral line mechanoreceptors ${ }^{108}$. That the brains were in good condition was manifested by normal responses to light and to mechanical stimuli, including water movement, touch and acoustic clicks, each in appropriate loci. In 14 tracks in two specimens of Lepisosteus osseus exploring the most likely parts of midbrain and medulla the result was the same.

Both Amia and Lepisosteus possess a lateralis column consisting of a medial octavolateralis nucleus (Fig. 1G) that receives input from the anterior and posterior lateral line nerves. The anterior lateral line nerve comprises a single entering root, and the medial octavolateralis nucleus is capped rostrally by a single granular cell group termed the eminentia granularis. Thus, the lateralis column in these species differs from that in chondrostean and polypteriform fishes by the absence of a dorsal root of the anterior lateral line nerve and a dorsal octavolateralis nucleus $^{78-81}$.

\subsubsection{Teleostei}

3.4.4.3.1. Anguilliformes. Claims have been published that eels can respond behaviorally to electric currents as low as $7 \mu \mathrm{V} / \mathrm{cm}$ or less ${ }^{19.99-101}$, but repeated efforts have failed to confirm these values ${ }^{13,35}$ The last named authors report behavioral thresholds of $0.5-2.4 \mathrm{mV} / \mathrm{cm}$, making these eels the nearest thing to transitional or intermediate animals with respect to electroreception, though not nearly as sensitive as the earlier authors believed. In the context of what signals might be encountered by a 'pre-electric' fish Lissmann ${ }^{68}$ reported that Anguilla gives an 'electrical disturbance' like a muscle action potential recordable $10 \mathrm{~cm}$ away, in response to a moving shadow.

In 6 specimens of Anguilla rostrata we explored 36 electrode tracks widely sampling the midbrain and the cerebellum and underlying medulla. Testing with 
electric fields from $100 \mu \mathrm{V} / \mathrm{cm}$ up to $10 \mathrm{mV} / \mathrm{cm}$ no evoked responses were found, although to photic stimuli they never failed, in the relevant loci. Our evidence does not support the attribution of transitional or intermediate sensitivity.

Anatomically the lateralis column of Anguilla consists of a medial octavolateralis nucleus that receives inputs from both the anterior and posterior lateral line nerves. The medial nucleus is continuous rostrally with the eminentia granularis as in other teleosts. There is no evidence of any specialization of the lateralis column such as occurs in those teleosts that are electroreceptive. Thus, the lateralis column in $A n$ guilla is similar to that in holosteans, and probably most teleosts.

\subsection{Salmoniformes. Rommel and Mc-} Cleave ${ }^{101}$ and Richardson et al. ${ }^{99}$ likewise claimed electrosensitivity for the Atlantic salmon, Salmo salar based on behavioral reactions.

In 4 specimens of one species of Pacific salmon, Oncorhynchus kisutch, of the same family (Salmonidae) in fresh water we explored 9 electrode tracks through midbrain, cerebellum and medulla. In two loci evoked potentials appeared with sharp thresholds of 40 and $50 \mathrm{mV} / \mathrm{cm}$ and in one other they appeared between 50 and $100 \mathrm{mV} / \mathrm{sm}$. To be certain that high intensity suppression was not preventing responses, weak stimuli were also tested, down to 50 $\mu \mathrm{V} / \mathrm{cm}$. The responses evoked by high intensity currents were not stimulus artifacts because, besides having sharp thresholds they were quite specific to electric field axis and polarity. Furthermore, they rapidly declined with stimulus repetition at 4 or 5 per second. We speculate that these are the responses of ordinary mechanoreceptive lateral line afferents, excited non-physiologically. Such thresholds are in the range of galvanotaxis of teleosts ${ }^{60}$.

Anatomically the lateralis column in Oncorhynchus and Salmo consists of a medial octavolateralis nucleus, and there is no evidence of any anatomical specialization such as occurs in the lateralis column of electroreceptive teleosts ${ }^{81}$.

3.4.4.3.3. Osteoglossiformes. Some years ago we tested electrophysiologically two species of the family Notopteridae, Asian knife fishes with a body form, fins and locomotion convergently similar to gymnoti- form electric fishes of South America. Notopterids are not electric, i.e. there is no specialized organ producing electric current pulses. We found no evidence of electroreception by the evoked potential method, exploring 18 electrode tracks in 6 specimens of $\mathrm{No}$ topterus notopterus and $N$. chitala with stimuli up to 5 $\mathrm{mV} / \mathrm{cm}$.

However, anatomical findings (see below) of Braford ${ }^{18}$ on a notopterid later found to belong to a different subfamily, from Africa, Xenomystus nigri, compelled re-examination physiologically.

Evoked potentials to weak electric pulses were found in nearly every electrode track in Xenomystus
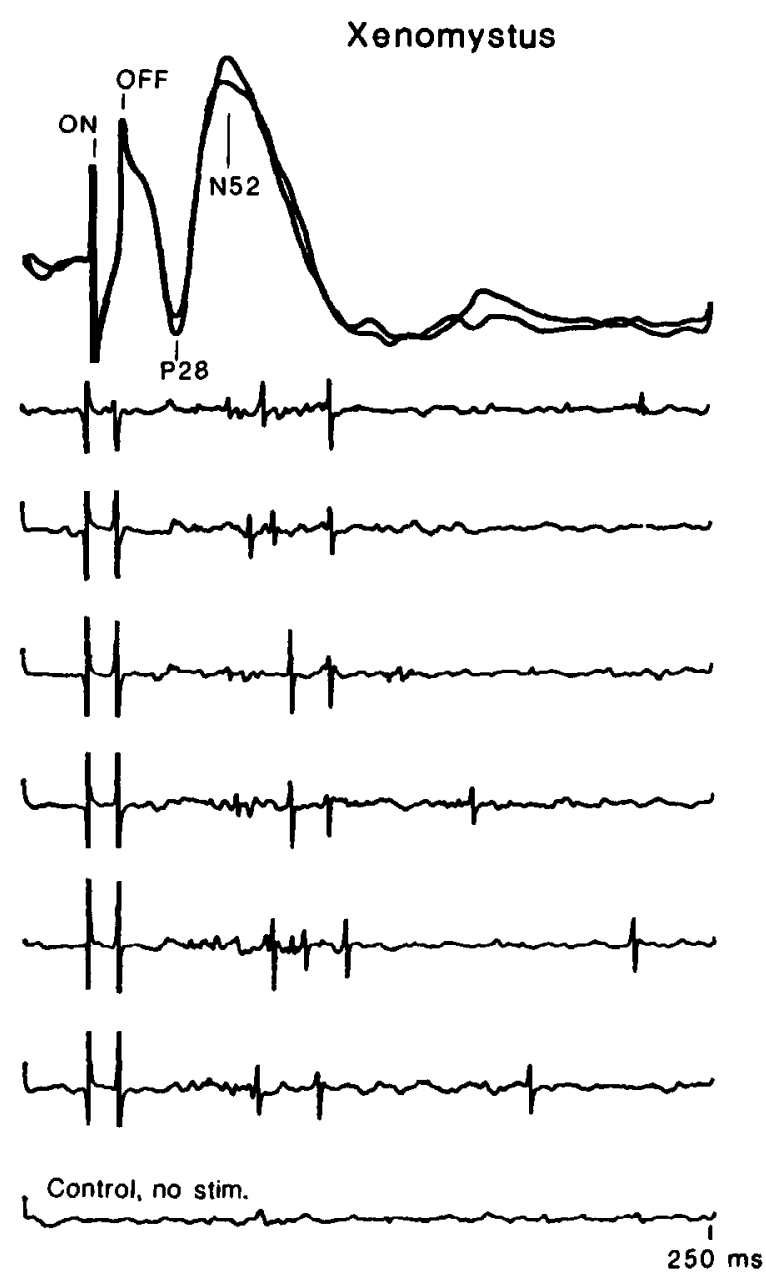

Fig. 4. Xenomystus. Activity of several units in the region of the torus semicircularis in response to a $12 \mathrm{~ms}$ pulse of $500 \mu \mathrm{V} / \mathrm{cm}$ in a favorable orientation. Six single sweeps with stimuli and one control without. A number of test sweeps without stimuli showed no spontaneous firing. (From Bullock and Northcutt ${ }^{26}$.) 
(Fig. 4) as reported elsewhere ${ }^{26}$. In 29 tracks in 4 animals the extent and depth of the responsive area were plotted. From 1 to $2.5 \mathrm{~mm}$ below the tectal surface in a large area but not near the midline or the far anterior or posterior mesencephalon, every electrode site was sensitive to stimuli of $<100 \mu \mathrm{V} / \mathrm{cm}$. The best loci respond to $<10 \mu \mathrm{V} / \mathrm{cm}$, with a clear preference for a certain axis and polarity. Like the well-known ampullary systems, response is nearly maximal with 10 or $20 \mathrm{~ms}$ pulses, but falls rapidly as the duration is reduced to $5 \mathrm{~ms}$ or less. Long pulses, e.g. $100 \mathrm{~ms}$ in duration gave maximal responses after $\mathrm{ON}$ in one polarity in the preferred field orientation. Reversing the polarity may not elicit the same response after OFF.

Anatomically two different patterns of organization characterize the lateralis column in the osteoglossiform fishes we examined. The most frequent pattern - which characterizes taxa in all families and is, therefore, the presumed primitive pattern - consists of a medial octavolateris nucleus that receives input from both anterior and posterior lateral line nerves. The medial nucleus is replaced rostrally by the eminentia granularis, and there is no evidence of any anatomical specialization associated with electroreception. Thus, most osteoglossiform fishes possess a lateralis column comparable to holosteans and the foregoing teleosts.

Notopterids exhibit this generalized pattern of lateralis organization only in the genus Notopterus of the subfamily Notopterinae. A second pattern is exhibited in two other genera; Xenomystus, as well as Papyrocranus $^{18}$ of the subfamily Xenomystinae, have a lateralis column divided into medial and lateral nuclei (Fig. 5A). The medial nucleus is histologically identical to the medial octavolateralis nucleus in other fishes and receives inputs from both anterior and posterior lateral line nerves. The lateral nucleus consists of a ventrally located neuropil capped dorsally by a distinct layer of Purkinje-like neurons. This lateral nucleus also receives inputs from both the anterior and posterior lateral line nerves and has been demonstrated physiologically to be an electroreceptive center ${ }^{26}$. This lateral electroreceptive nucleus of the lateralis column is termed the electrosensory lateral line lobe, ELLL. Heretofore, electroreception has always been a characteristic believed to be general for all members of an order, if not a larger taxon.
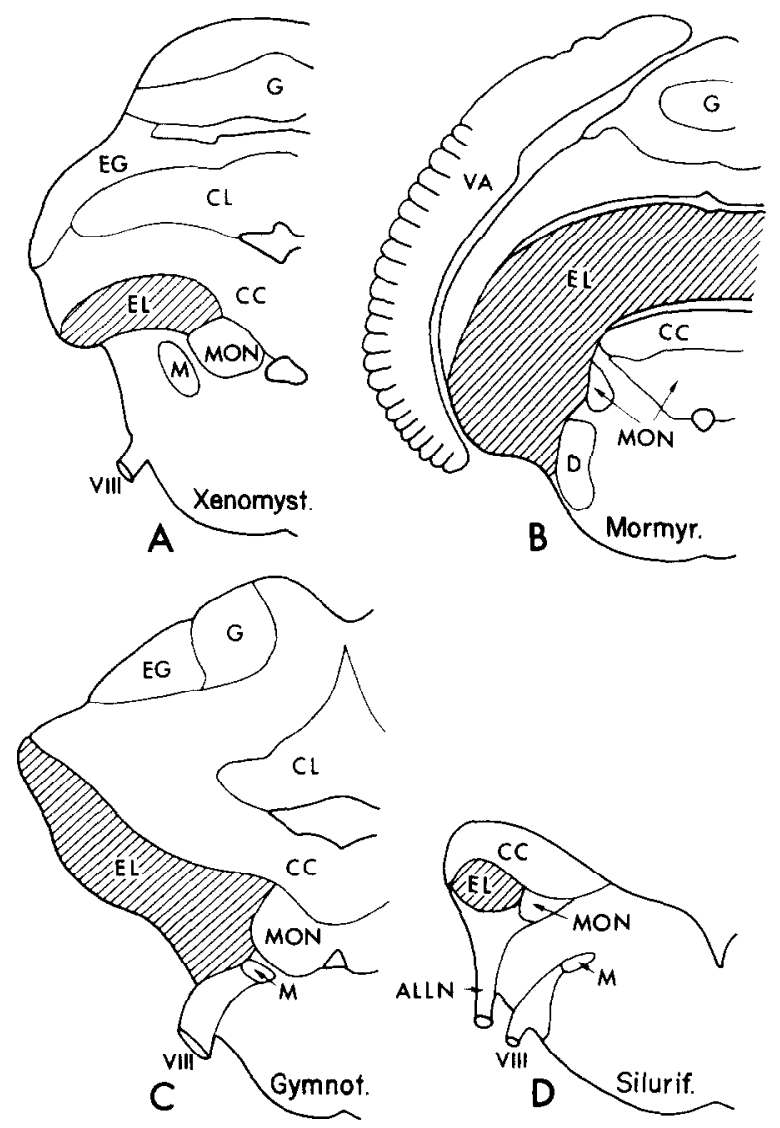

Fig. 5. Variation in the octavolateral area of the medulla in electroreceptive teleost fishes seen in diagrammatic transverse sections of one side of the medulla. Drawings are not to the same scale. Shaded areas, ELLL, the first electroreceptive nucleus, including both ampullary and tuberous portions. A: Xenomystus. B: Gnathonemus. C: Eigenmannia. D: Ictalurus. Abbreviations: ALLN, anterior latetal line nerve; $C C$, cerebellar crest; $\mathrm{CL}$, caudal lobe of cerebellum; D, descending octaval nucleus; EG, eminentia granularis; EL, electrosensory lateral line lobe; $G$, granular layer of cerebellum; $M$, magnocellular octaval nucleus; MON, medial octavolateral nucleus; VA, valvula of cerebellum; VIII, octaval nerve.

The clear development of physiological and anatomical specialization for this modality in one subfamily of a large order is a unique situation among the groups so far known. Of course we cannot on the evidence choose between the possibilities that this modality was invented in the subfamily Xenomystinae and that it was invented in ancestors of all Notopteridae and secondarily lost in notopterines. The third possibility that it was inherited by ancestral osteoglossiforms from the same ancient osteoglossimorphs that passed the trait to the mormyriforms would require several independent losses. 
3.4.4.3.4. Mormyriformes. This order of African freshwater fishes is considered to be related to the preceding. The entire order, with its monospecific family Gymnarchidae and the large family Mormyridae is both electric and electroreceptive. It suffices here to refer to some of the classical papers $5,37,69,71,72,109$ and a few reviews $2,6,9,21,110,111,116$.

Evoked potential data comparable to that here reported for other orders is not available because mormyriforms have evolved a second major class of electroreceptors and central structures in addition to the low frequency-sensitive ampullary system, namely those specialized for electric events of relatively high frequency content - the tuberous sense organs and their medullary, midbrain and cerebellar centers. Only the ampullary system is comparable to the electroreceptors and their central pathways in the nonelectric teleosts and in non-teleosts. In mormyriforms we could presumably stimulate ampullary organs alone by using low frequency sine waves, but the evoked potential picture would be quite different from our usual square pulse stimulation. This method has not yet been exploited. Behavioral evidence of the distinction between ampullary and tuberous function in electric fish was evaluated by Kalmijn ${ }^{60}$.

Anatomically all mormyriform fishes examined exhibit a lateralis column divided into medial and lateral divisions (Fig. 5B) formerly termed the anterior and posterior lateral line lobes, respectively. The medial division is histologically similar to the medial octavolateralis nucleus in holosteans and nonelectroreceptive teleosts and is probably homologous to this nucleus. The lateral division is a well differentiated, laminated structure known to be the primary target of entering electroreceptor afferents $3,4,72-75$. The descriptive term, electrosensory lateral line lobe, ELLL, is now used for this lateral subdivision in preference to the older term, posterior lateral line lobe, which implies incorrectly an homology with the lobe of the same name in nonteleost fishes.

3.4.4.3.5. Cypriniformes. There is no indication for electroreception in the carps and their allies. Kalmijn ${ }^{60}$ summarizes old literature on galvanotaxis in which the 'first reaction' in various cyprinids has a threshold from 5.5 to $125 \mathrm{mV} / \mathrm{cm}$. We have tested 7 specimens belonging to 3 genera (Table II) by the evoked potential technique and found no response to electric fields from $100 \mu \mathrm{V} / \mathrm{cm}$ to $2 \mathrm{mV} / \mathrm{cm}$ at any depth in many penetrations through the regions of the octavolateral medulla and the torus semicircularis. These are the closest relatives of the electroreceptive siluriforms and gymnotiforms; together with a few other groups these taxa comprise the Ostariophysi.

The lateralis column in the cypriniform species we examined (Table II) comprises only a medial octavolateralis nucleus, and there is no evidence of any anatomical specialization that might be associated with electroreceptive functions.

3.4.4.3.6. Gymnotiformes. Following $\mathrm{Mago}^{70}$, we recognize 6 families in this South American group of electric fishes, and treat it as an order. The large number of species, forming a conspicuous part of the fish fauna in the tropical new world, in many kinds of freshwater habitats, clear and turbid, fast moving and stagnant, all have in common weak electric organ discharges and electroreception. Like the mormyriforms, their counterparts in Africa, they are usually discharging at some rate from a few per minute up to many times per second all the time, night and day and utilize two parallel electrosensory systems, an ampullary low-frequency sensitive and a tuberous high-frequency sensitive system of sense organs and brain structures. The evidence of their electroreception, first shown behaviorally by Lissmann ${ }^{68}$ and attributed to a component of the lateral line by section of nerve branches by Bennett and Grundfest $^{11}$, then studied physiologically by Bullock et al.28, Hagiwara and associates ${ }^{46,47}$, Suga 107,108 and Bennett ${ }^{7}$, has been reviewed several times $2,6,8,9,21,38,48,49,60,104,110.111,116$. More recent detailed studies of the physiology include, among others Partridge et al. ${ }^{96}$ and Heiligenberg and Partridge ${ }^{52}$.

Electrophysiological studics of the medullary, midbrain and cerebellar centers have been numerous (refs. above) and chiefly deal with the tuberous, high-frequency sensitive system, as in mormyriforms. Briefly, we know that the ELLL and an enlarged, specialized part of the TS are electroreceptive, in addition to the nucleus pre-eminentialis and special parts of the cerebellum. In most of these structures there are separate centers for ampullary and tuberous systems and even subdivisions for the input from different subsystems of tuberous receptors. Parallel processing is well developed for submodalities in the octavolateralis system. 
Anatomically all gymnotiform fishes examined exhibit a lateralis column divided into medial and lateral divisions (Fig. 5C), termed the anterior and posterior lateral line lobes, respectively. These divisions are superficially similar to those in mormyriform fish$\mathrm{es}$, and the medial nucleus in gymnotiforms is probably homologous to the medial octavolateralis nucleus in other teleosts. The lateral nucleus in gymnotiforms is an electroreceptive nucleus and is now called the ELLL or electrosensory lateral line lobe29,51,74,75. In this order it receives input only from the anterior lateral line nerve, whereas in mormyriforms and xenomystines as well as siluriforms it receives electroreceptor input from both anterior and posterior lateral line nerves.

3.4.4.3.7. Siluriformes. This large and world-wide group of some 30 families, mostly freshwater but a few marine, are probably all electroreceptive; only one genus (Malapterurus) is known to be electric. Early evidence is reviewed by Kalmijn ${ }^{60}$ and recent studies by Bullock ${ }^{21}$. Lacking the tuberous class of receptors, this has been the preferred group for studying the anatomy and physiology of a teleost ampul- lary system; a good deal is known, including single unit physiology, both peripheral and central. For comparison with other groups a brief recapitulation of the evoked potential data is in order.

In the torus semicircularis of Ictalurus, in response to a moderately strong $(0.5 \mathrm{mV} / \mathrm{cm})$ pulse as a homogeneous field of duration longer than the response, Knudsen ${ }^{63}$ described a principal wave, N14-19. A stronger stimulus in another species and locus (Fig. 6) brings out small N15, P19, a large N24, P32 sequence and a slow $\mathrm{N} 50$ - if the axis and polarity of the electric field conform to the preferences of that locus ${ }^{20}$. Based on recordings from 11 species in $6 \mathrm{fam}$ ilies the most general statement is that a small initial peak at 20-25 ms may be followed by one at $30-35$ $\mathrm{ms}$, a main wave at $45-50 \mathrm{~ms}$ and sometimes a late one at $65-80 \mathrm{~ms}$. The polarities of most of these waves can be either $N$ or $P$, depending on locus. Spike bursts are typically centered around maxima at $10-20 \mathrm{~ms}$ and $200-300 \mathrm{~ms}^{64}$. Differences in response characteristics in different parts of the torus and dynamics of the response with stimulus repetition are given by Knudsen ${ }^{63-66}$.
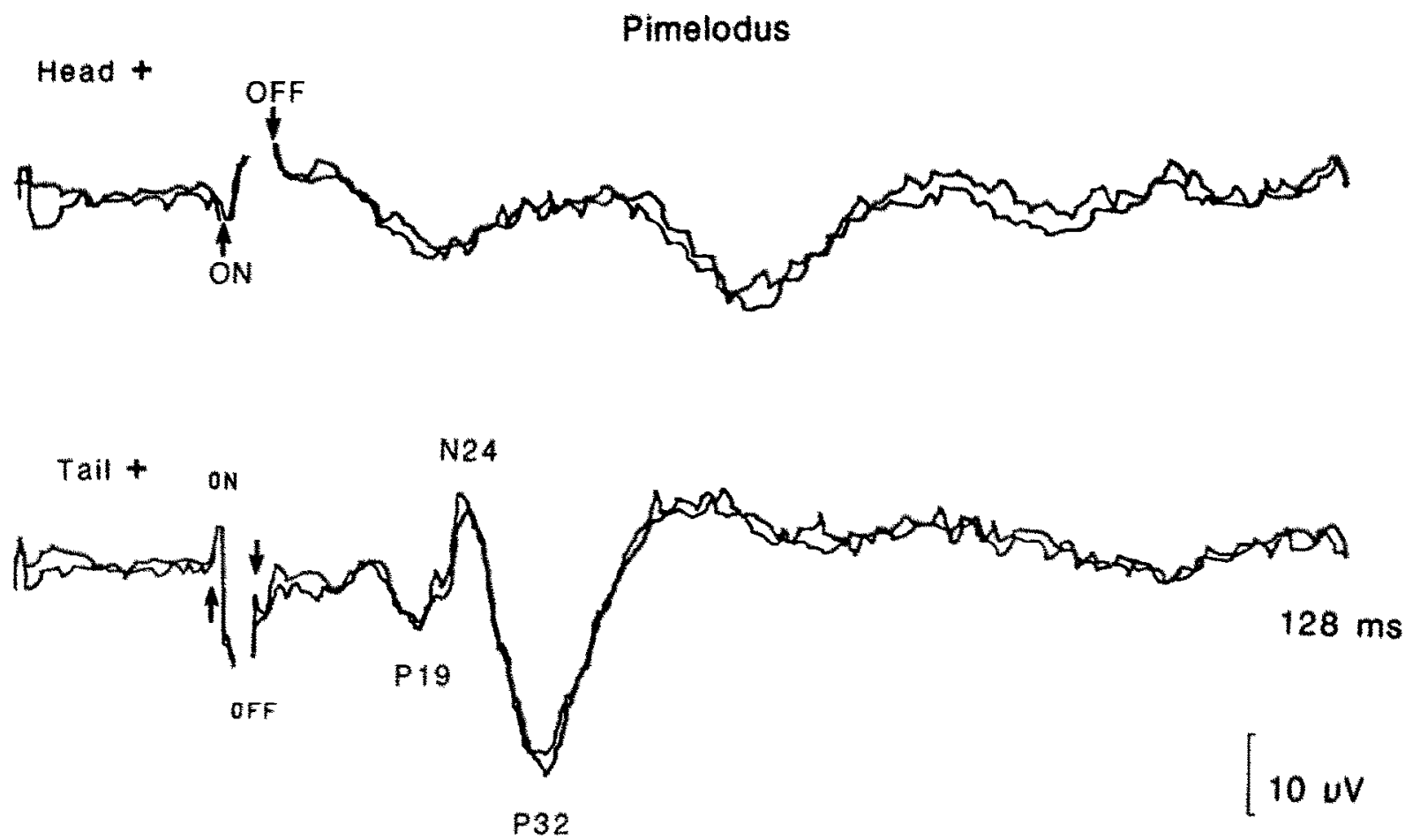

Fig. 6. Pimelodus sp. (Siluriformes). Two superimposed average evoked potentials from the region of the torus semiciroularis sponse to a $3.6 \mathrm{~ms}$ longitudinal pulse in each of the two polarities, showing the marked sensitivity of this brain locus to current direction. (From Bullock ${ }^{20}$.) 
Evoked potentials in the medulla and cerebellum are briefly described in Bullock ${ }^{20}$. Several authors have studied units in these regions $\mathbf{s}^{1,2,21,113,114}$.

Anatomically, all siluriform fishes examined (Table II) exhibit a lateralis column divided into medial and lateral divisions (Fig. 5D) ${ }^{115}$. Both divisions receive inputs from the anterior and posterior lateral line nerves, and the lateral division has been demonstrated physiologically to be an electroreceptive nucleus (S.-L. Tong, personal communication). Thus, it appears reasonable to designate the lateral nucleus as an electrosensory lateral line lobe. The medial nucleus is probably a mechanoreceptive area homologous to the medial octavolateralis nucleus in other fishes.

3.4.4.3.8. Synbranchiformes. We have had the opportunity to record from two specimens of Synbranchus marmoratus, through the courtesy of J. B. Graham. This burrowing, nocturnal swamp-eel from tropical America is in a somewhat isolated taxonomic position. Testing with $5 \mathrm{~ms}$ electric pulses up to 3 $\mathrm{mV} / \mathrm{cm}$, no evoked potential was found in more than 18 electrode tracks through the midbrain, cerebellum and medulla, although good photic responses, tactile and spontaneous unit activity were encountered.

The lateralis column of Synbranchus consists of a medial octavolateralis nucleus that receives inputs from both lateral line nerves. There is no evidence of any anatomical specialization that might be associated with electroreception.

3.4.4.3.9. Perciformes. One genus, Astroscopus, out of 8 genera in the marine family of stargazers, Uranoscopidae, is a classical electric fish, with electric organs derived from portions of the extrinsic ocular muscles. There appears to be no evidence or test of electroreception, nor is there an obvious or recognized function for the electric discharge. The discharge (Pickens and MacFarland, see ref. 21) is to be mainly a brief burst at the moment of prey capture, is probably too weak to be offensive or defensive ${ }^{12}$, and too late to be of value as a sensory probe guiding the prey capture. There is a suggestion of social communication in a reported seasonality of the discharge 83.84 . This may be connected with seasonal movements 32 .

In 4 specimens we have looked for electric evoked potentials in 44 electrode tracks. Testing usually with $10 \mathrm{~ms}$ pulses up to $400 \mu \mathrm{V} / \mathrm{cm}$, as homogeneous fields and with local, hand-held electrodes exploring the body surface, with currents up to $5 \mathrm{~mA}$, no electric evoked potentials have been obtained. In various loci responses have been seen, as evoked potentials, hash or multiunit firing to light flashes, vibration, acoustic clicks, water movement and touch, giving evidence that the preparation was in good condition. Presumably at some higher intensity than we used the common lateral line or segmental skin afferents would be stimulated non-specifically. The threshold for such excitation should be ascertained since the electric organ discharge of the same or of a neighboring Astroscopus might well exceed it.

Similar tests have been performed on two cichlids of the species Astronotus ocellatus, with the same results, i.e. no evidence of electroreception.

In the 5 perciform species we examined anatomically, including Astroscopus, the lateralis column comprises only a medial octavolateralis nucleus, and there is no evidence of any anatomical specialization that might be associated with electroreception.

3.4.4.3.10. Pleuronectiformes. Only a single specimen of the butter sole, Isopsetta, has been studied by the evoked potential method. Many loci in the midbrain were examined without finding any electroreception although good responses to acoustic and photic stimuli showed the condition of the preparation to be suitable.

\subsection{Amphibia}

\subsubsection{Urodela}

Fritzsch ${ }^{40,41}$, Münz et al. ${ }^{85}$ and Fritzsch and Wahnschaffe ${ }^{43}$ have shown electroreception physiologically in urodele amphibians (Ambystoma, axolotl) and have described ampullary sense organs which they consider to be the electroreceptors in these and in species of another suborder (Salamandra, Triturus). Himstedt et al. ${ }^{54}$ have demonstrated electroreception behaviorally in the same species. The threshold sensitivity of single fibers of the anterior lateral line nerve to square pulses of $0.5 \mathrm{~s}$ is stated to be 100 $\mu \mathrm{V} / \mathrm{cm}$ or less. This is not an extremely high sensitivity but, for single afferent fibers is quite adequate to justify the conclusion of electroreception. The behavioral threshold was $<25 \mu \mathrm{V} / \mathrm{cm}^{54}$. The response is excitatory when the cathode is in front of the head, where the receptors are, and the anode is 
behind the tail 85 . This is the same as the case in nonteleost fishes, including the lungfish which is presumably the closest to amphibian ancestors, in contrast to the anodal excitatory polarity of electroreceptive teleosts. Fritzsch and Wahnschaffe ${ }^{43}$ have described the light and electron microscopy of the ampullary sense organs. The receptor cells have no kinocilium but many microvilli. This contrasts with the available information on elasmobranchs, but our knowledge of the electron microscopy of the diverse non-teleosts is fragmentary. Lungfish and perhaps others have microvilli. Loss of the kinocilium is evidently compatible with electroreception. These cytological characters in urodele ampullae resemble those of teleosts, showing that they are not good characters for indicating homology. The ampullary afferents according to Fritzsch are confined to the anterior lateral line nerve and are segregated in a dorsal projection into a 'dorsal island of Kingsbury' of the medulla. This structure was identified a few years ago by Opdam and Nieuwenhuys ${ }^{95}$ as homologous to the dorsal nucleus, DN, which we now know as the electroreceptor nucleus of elasmobranchs and most other non-teleost fishes.

\subsubsection{Apoda (Caecilia, Gymnophiona)}

Apoda require new attention. The suggestion made by $\mathrm{Coggi}{ }^{36}$ that they may have electroreception was based on tenuous histological evidence of skin sense organs reminiscent of ampullary organs. Hetherington and Wake ${ }^{53}$ provided somewhat better evidence but it is still confined to the histological similarity of pit organs in the skin to ampullary organs in electroreceptive teleosts, surely independent inventions at best. It is only one family of the apodans or caecilians that is suspected to possess this trait, the aquatic Ichthyophiidae, and only the larval stages since the adults lose the lateral line. It would be important to examine the medulla for signs of a dorsal nucleus, pending opportunity to test these larvae physiologically or behaviorally.

On the hypothesis presented here that electroreception was general in the non-teleost fishes, we can assume primitive amphibians had it as a heritage from their ancestors, whether those were closer to lungish or to crossopterygians, since both of these are electroreceptive. This interpretation is compatible with the assumption of electroreception in fossil ancestors of Amphibia ${ }^{94}$, unless secondarily lost.
We have confirmed the presence of a medullary nucleus which can be called a dorsal octavolateral nucleus, DN in the adult Ambystoma tigrinum (suborder Ambystomatoidea), in our own material. In addition we find this nucleus well developed in Amphiuma means (Salamondroidea). The interpretation of the structure in Necturus maculosus (Proteida) is not yet clear. Cryptobranchus alleganiensis (Cryptobranchoidea) appears not to have a DN. We have not examined material of the Sirenoidea (Meantes). Thus two of the 5 suborders of urodeles clearly have electroreception, with both peripheral and central specializations.

\section{DISCUSSION}

Our examination of the lateralis column of the medulla in a wide array of fishes and amphibians reveals at least 3 basic organizational patterns. (a) Petromyzoniform, cartilaginous, chondrostean, polypteriform, crossopterygian, and dipneustian fishes as well as ambystomatoid and salamandroid urodeles are characterized by a dorsal as well as a medial octavolateralis nucleus and by an anterior lateral line nerve divided into dorsal and ventral roots which innervate the dorsal and medial nuclei, respectively. (b) Holostean and most orders of teleost fishes are characterized by having only a medial octavolateralis nucleus and an anterior lateral line nerve with a single root. This may also be true of cryptobranchoid urodeles. This second pattern is likely to be the result of secondary simplification, derived from the first pattern. (c) Xenomystinid, mormyriform, gymnotiform, and siluriform teleosts are characterized by a lateralis column divided into lateral and medial divisions, with the lateral division constituting an clectroreceptive area termed the electrosensory lateral line lobe. The medial division is probably homologous, at least in part, to the mechanoreceptive medial octavolateralis nucleus in other taxa. This pattern appears to be a tertiary evolutionary stage, developed out of the second.

The first pattern has been reported previously in most non-teleost taxa $17,55,56,67,79-81,82,90,92,103,105$ and in ambystomatoid and salamandroid urodeles ${ }^{40,41.95}$. Its wide distribution, as well as its sole occurrence in cartilaginous and primitive bony fishes, led McCormick ${ }^{80,81}$ to conclude that this must be the ancestral 
pattern for vertebrates. Equally important, McCormick hypothesized that the dorsal octavolateralis nucleus in these taxa is an electroreceptive nucleus, based on an earlier hypothesis regarding this nucleus in elasmobranch fishes ${ }^{17,82}$. Earlier electrophysiological studies ${ }^{15,16}$, as well as data presented here, clearly confirm these hypotheses. Reasonably good information for 4 of the suborders of urodele amphibians shows that this pattern has been inherited in at least two of them and probably secondarily lost in at least one, the cryptobranchoids. The situation is not yet clear in proteidans. All the major taxa with this pattern have now been examined electrophysiologically and positive evidence of electroreception has been found.

The organization of the lateralis system in myxiniform fishes is poorly understood. The anterior lateral line nerves do not possess distinct dorsal and ventral roots, nor is a posterior lateral line nerve or a dorsal octavolateralis nucleus apparent. Experimental studies are required to determine the details of lateralis organization but, at present, there is no evidence of any anatomical specialization that might be correlated with electroreception. Again, the physiological evidence is in agreement, although being negative evidence, it is not by itself so convincing.

The second lateralis pattern has been reported previously in holosteans and many teleosts ${ }^{79-81,97}$. McCormick hypothesized that living holosteans must represent a grade of ray-finned fishes that lost electroreception and, thus, the dorsal octavolateralis nucleus. Our anatomical and physiological data clearly confirm her hypothesis. Possibly this is the pattern for the great majority of teleosts. It also describes the situation in amphibians that have lost electroreception, including cryptobranchoids and terrestrial urodeles and anurans. Larval anurans are not yet known sufficiently to categorize their pattern.

The third lateralis pattern, which occurs in electroreceptive teleosts, is particularly intriguing from an evolutionary viewpoint. There are sufficient physiological and anatomical data to indicate that all teleost taxa known to be electroreceptive exhibit a lateral division of the lateralis column which is associated with this sensory modality and which is unknown in other taxa. In the earliest studies of electroreceptive medullary structures ${ }^{14,106}$, it was called the posterior lateral line lobe, a term that is also applied to the mech- anoreceptive medial octavolateralis nucleus in cartilaginous fishes. McCormick ${ }^{81}$ examined in detail the anatomical and functional inconsistencies of such homology and concluded that the electroreceptive area of the lateralis column in teleosts can not be homologous to the dorsal octavolateralis nucleus in other fishes. Furthermore, the distribution of an electrosensory lateral line lobe among various teleost radiations strongly suggests that it is an independently derived character and, therefore, a homoplastic one.

The principal result of the present survey is that the sense modality of electroreception and its associated central structures are found in a wide assortment of taxa but are absent in many others (Fig. 7). Although direct evidence for most orders of teleosts is lacking, the indirect evidence is that the great majority lack these characters. Of the non-teleosts only the Myxiniformes and Holostei appear to lack them. Cryptobranchoids and possibly some other aquatic urodeles as well as terrestrial amphibians appear to lack them.

Remarkably, there are no clearly borderline or transitional fishes, with respect to these characters, physiologically or anatomically. Such fishes would

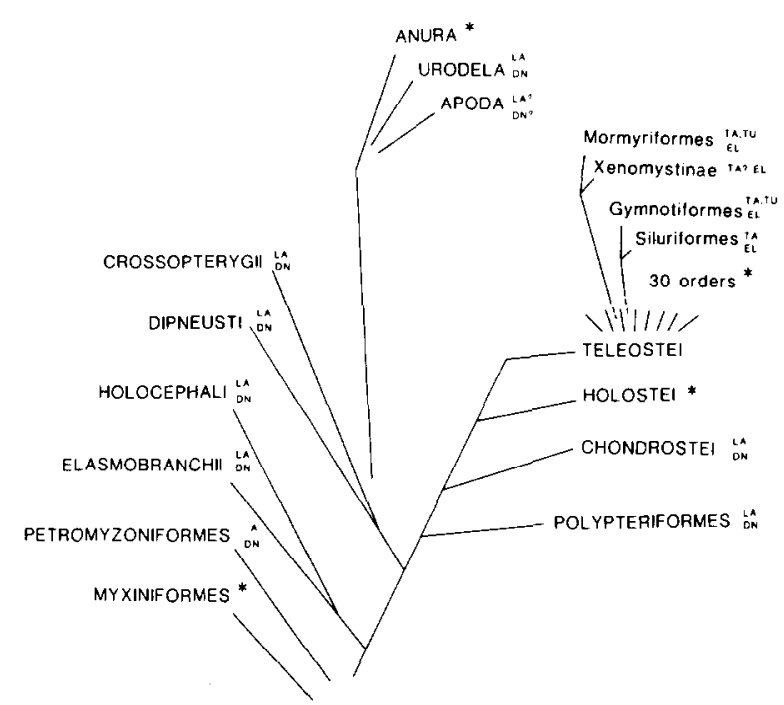

Fig. 7. The distribution of the different kinds of electrorecep tive systems among the major groups of living fishes and amphibians. DN, possessing a dorsal octavolateral nucleus; EL, electrosensory lateral line lobe; LA, Lorenzinian type of ampullae; TA, teleost type of ampullae; TU, tuberous electroreceptors; ?, suspected but not demonstrated; *, believed to lack electroreceptors and their brain centers, sometimes with negative evidence, often without evidence (see text). (Modified from Bullock et al. ${ }^{27}$.) 
have evoked potential thresholds in the range of tenths of a millivolt per centimeter or lower, or behavioral thresholds of microvolts to a few tens of microvolts per centimeter, or some anatomical suggestion of an incipient lateral nuclear differentiation in the medulla suggestive of a dorsal nucleus or an electrosensory lateral line lobe. In making comparisons of thresholds it is important to distinguish behavioral thresholds, which can be the lowest, from those for evoked potentials which are commonly intermediate, and those for single receptors or afferent fibers, which are usually the highest.

The closest case to a transitional or borderline animal is the eel, Anguilla, where behavioral thresholds as low as $0.5 \mathrm{mV} / \mathrm{cm}^{13,35}$ have been reported. This is 5000-100,000 times the behavioral thresholds of siluriforms and elasmobranchs ${ }^{60-62}$. We do not have equivalent behavioral tests on a variety of fishes without electroreceptive specialization. (We have above rejected the claims of extremely high sensitivity in eels and salmon since repeated later tests, both behavioral and physiological, have failed to confirm them.) In the face of the negative physiological and anatomical evidence, we cannot consider either eels or salmon as specialized for naturally occurring electroreception. Most of the obvious natural signals ${ }^{60}$ are likely to be much less than $0.5 \mathrm{mV} / \mathrm{cm}$. We cannot dismiss the possibilities of (a) some kind of social signals from unusually synchronized muscle potentials in very near-by partners, as suggested by Lissmann ${ }^{68}$ and (b) some kind of central summation of the high threshold excitability of common lateral line receptors to electric current (receptor thresholds from data on other species $=>10 \mathrm{mV} / \mathrm{cm}$ ), although our method is a spatial and temporal averaging technique that should pick up most such central responses.

The distribution of electroreception among nontcleosts suggests that it was a primitive characteristic among vertebrates. We cannot speculate as yet whether its apparent absence in myxiniforms is even more primitive or is a secondary loss. This question is bound up with the problem of whether to regard the hagfishes as possessing an exceedingly meager incipient lateral line system or a reduced remnant - an issue beyond our scope here.

The implication of the above is that the ampullary receptors, the dorsal roots and dorsal nuclei and electroreceptive parts of the praeeminentialis, cerebel- lum, torus semicircularis and yet to be identified diencephalic and telencephalic nuclei of all the nonteleosts, except for myxiniforms and holosteans, are either homologous or structures of very similar form and function that were repeatedly invented. The former seems to be the most parsimonious assumption.

In teleosts the situation is quite different. It seems likely that electroreception and associated structures are developed only in members of 4 orders of the 33 or so: probably all siluriforms, gymnotiforms and mormyriforms and a few osteoglossiforms, the xenomystines. Direct tests, by the evoked potential method have been done only on representatives of 5 other orders, with negative results. Failure to find electroreception physiologically or a distinctive differentiation histologically can not be unequivocal proof of absence of this sense modality. However, from the good number of species in all of which the two methods correlate with each other, we have acquired a certain degree of confidence in each of them. Although we have not listed all the species of teleosts whose medulla is more or less known anatomically, from the literature and from the extensive personal collections we have studied in other connections, the weight of negative evidence, with respect to specialized nuclei lateral to the usual medial octavolateral nucleus, is not inconsiderable. It is quite possible that here or there another electroreceptive taxon will turn up. Still, it appears likely that the great majority of teleosts lack this modality.

The implication of this is that electroreception evolved in either of two ways, or a mixture of them. (a) It might have been a common heritage, in which case it had to be lost again and again, many times independently such that the stock from which widely unrelated electroreccptive taxa developed still possessed the whole set of traits, while the great majority of taxa that came from these stocks lost it. The minimum number of branch points where independent losses would have to be assumed depends on the teleost cladogram one accepts. It would certainly be a large number. Therefore we find it more parsimonious to believe that (b) the electroreceptive system was lost once in the common ancestors of holosteans and teleosts and later reinvented independently a few times. The number of times is not easy to be sure of. Since mormyriforms and gymnotiforms are so far apart in teleost taxonomy, it must be at least 
two and more probably 3 or 4 . Conceivably siluriforms and gymnotiforms shared one invention of this character-set, with or without a secondary loss in cypriniforms and characoids, depending on the timing of the invention. Conceivably mormyriforms and xenomystine notopterids might have shared one invention of a somewhat similar character set, but this would require either (a) the assumption of a series of independent losses of the whole system in several osteoglossiform stems or (b) the assumption of a common ancestor of Xenomystinae and Mormyriformes not shared by Notopterinae and other osteoglossiforms. Neither of these is clearly more parsimonious than the assumption of independent inventions. It is not to be assumed from the commonality of anatomical terms among 4 teleost taxa (teleostean ampullary receptors, tuberous receptors, ELLL) that these structures are homologous in the strictest sense.

The phyletic origin of the electrosensory lateral line lobes of electroreceptive teleosts is presently unclear. The simplest hypothesis is that at least one class of mechanoreceptors in an ancestral teleost population was selected for increased electrical sensitivity of their cellular basal surfaces, converting these mechanoreceptors into a new class of electroreceptors. Concomitantly, the region within the medial octavolateralis nucleus that received the afferent fibers of these new electroreceptors would have enlarged and differentiated in distinctive ways in the several electroreceptive orders thereby developing an electrosensory lateral line lobe, ELLL, as part of the medial nucleus. More rostral centers and pathways associated with this portion of the medial nucleus would simultaneously develop. If true, a corollary of this hypothesis is that the ELLL and medial nucleus in electroreceptive fishes are field homologs of the medial nucleus in other teleosts ${ }^{92}$.

This hypothesis assumes that teleost electroreceptors evolved from an ancestral population of lateral line mechanoreceptors, although it is possible that teleost electroreceptors and their central pathways arose from other cell lineages. The latter possibility is unlikely, however, as the afferent fibers of teleost electroreceptors form part of the lateral line nerves, suggesting that the receptors and their sensory ganglia arose from the same placodal tissue as other components of the lateral line system.

\section{SUMMARY}

Specializations for electroreception in sense organs and brain centers are found in a wide variety of fishes and amphibians, though probably in a small minority of teleost taxa. No other group of vertebrates or invertebrates is presently suspected to have adaptations for electroreception in the definition given here. The distribution among fishes is unlike any other sense modality in that it has apparently been invented, lost completely and reinvented several times independently, using distinct receptors and central nuclei in the medulla. There are so far no clearly borderline or transitional fishes, either physiologically or anatomically. We rather expect a few new electroreceptive taxa to be found. The evoked potential method and the newly validated central anatomical criteria provide two useful tools for searching.

Although Myxiniformes probably lack electroreception, it is well developed in Petromyzoniformes and in all other non-teleost fishes except Holostei. Thus Elasmobranchia, Holocephala, Dipneusti, Crossopterygii, Polypteriformes and Chondrostei have the physiological and anatomical specializations in a common form consistent with a single origin in primitive vertebrates. Amphibian ancestors probably inherited the system from a stem similar to one of these and passed it on at least to the ambystomatoid and salamandroid urodeles, apparently after losing the kinocilium of the sense cell. The suggestion of electroreception in ichthyophid apodans from skin histology has not been confirmed physiologically, behaviorally or by brain anatomy. With respect to more advanced fishes the most parsimonious interpretation is that the cntirc system, periphcral and central was lost in ancestors of holostean and teleostean fishes and new systems reinvented in Siluriformes, in Gymnotiformes, in Xenomystinae and in Mormyriformes. These 4 taxa must represent at least two, and probably 3 or 4 independent inventions, presumably from mechanoreceptive lateral line organs and brain centers.

\section{ACKNOWLEDGEMENTS}

Aided by grants from the National Institutes of Health and the National Science Foundation. 


\section{REFERENCES*}

1 Adrianov, G. N. and Enin, L. D., Acoustico-lateralis system. Morphological and functional properties of cerebral structures of the lateral line system in fish. In Sensory Systems, Nauka, Leningrad, 1977, pp. 125-146 (in Russian).

2 Bell, C. C., Central nervous system. Physiology of electroreception, a review, J. Physiol. (Paris), 75 (1979) 361-379.

3 Bell, C. C., Central distribution of octavolateral afferents and efferents in a teleost (Mormyridae), J. comp. Neurol., 95 (1981) 391-414

4 Bell, C. C., Finger, T. E. and Russell, C. J., Central connections of the posterior lateral line lobe in mormyrid fish, Exp. Brain Res., 42 (1981) 9-22.

5 Bennett, M. V. L., Electroreceptors in mormyrids, Cold Spr. Harb. Symp. quant. Biol., 30 (1965) 245-262.

6 Bennett, M. V. L., Mechanisms of electroreception. In P. Cahn (Ed.), Lateral Line Detectors, Indiana Univ. Press, Bloomington, IN, 1967, pp. 313-393.

7 Bennett, M. V. L., Similarities between chemically and electrically mediated transmission. In F. D. Carlson (Ed.), Physiological and Biochemical Aspects of Nervous Integration, Prentice-Hall, Englewood Cliffs, NJ, 1968, pp. 73-128.

8 Bennett, M. V. L., Comparative physiology: electric organs, Ann. Rev. Physiol., 32 (1970) 471-528.

9 Bennett, M. V. L., Electrolocation in fish, Ann. NY Acad. Sci., 188, (1971) 242-269.

10 Bennett, M. V. L., Electroreception. In W. S. Hoar and D. S. Randall (Eds.), Fish Physiology, Academic Press, New York, 1971, pp. 493-574.

11 Bennett, M. V. L. and Grundfest, H., Electrophysiology of electric organ in Gymnotus carapo, J. gen. Physiol., 42 (1959) 1067-1104.

12 Bennett, M. V. L. and Grundfest, H., The electrophysiology of electric organs of marine electric fishes. III. The electroplaques of the stargazer, Astroscopus y-graecum, J. gen. Physiol., 44 (1961) 819-843.

13 Berge, J. A., The perception of weak electric A.C. currents by the European eel, Anguilla anguilla, Comp. Bio chem. Physiol. A, 62 (1979) 915-919.

14 Berkelbach van der Sprenkel, $H$., The central relations of the cranial nerves in Siluris glanis and Mormyrus caschive J. comp. Neurol., 25 (1915) 5-65

15 Bodznick, D. A. and Northcutt, R. G., Segregation of electro- and mechanoreceptive inputs to the elasmobranch medulla, Brain Res., 195 (1980) 313-321.

16 Bodznick, D. A. and Northcutt, R. G., Electroreception in lampreys: evidence that the earliest vertebrates were electroreceptive, Science, 212 (1981) 465-467.

17 Boord, R. L. and Campbell, C. B. G., Structural and functional organization of the lateral line system of sharks, Amer. Zool., 17 (1977) 431-441.

18 Braford, M. R., Jr., African, but not Asian, notopterid fishes are electroreceptive: evidence from brain characters, Neurosci. Lett., 32 (1982) 35-39

19 Branover, G. G., Vasil'yev, A. S., Gleizer, S. I. and Tsinober, A. B., A study of the behavior of eels in natural and artificial magnetic fields and an analysis of its reception mechanism, J. Icthyol., 11 (1971) 608-614.
20 Bullock, T. H., Processing of ampullary input in the brain: comparisons of sensitivity and evoked responses among siluroids and elasmobranchs, J. Physiol. (Paris), 75 (1979) 397-407.

21 Bullock, T. H., Electroreception, Ann. Rev. Neurosci., 5 (1982) $121-170$,

22 Bullock, T. H., Physiology of the tectum mesencephali in elasmobranchs. In H. Vanegas (Ed.), The Vertebrate Tectum, Plenum Press, New York, in press.

23 Bullock, T. H. and Bodznick, D. A., Electroreception in chimera (Holocephali): responses in the CNS, Soc. Neurosci. Abstr., 8 (1982) 1026 (abstr.).

24 Bullock, T. H. and Corwin, J. T., Acoustic evoked activity in the brain of sharks, J. comp. Physiol., 129 (1979) 223-234.

25 Bullock, T. H., Behrend, K. and Heiligenberg, W., Comparison of the jamming avoidance responses in gymnotoid and gymnarchid electric fish: a case of convergent evolution of behavior and its sensory basis, J. comp. Physiol., 103 (1975) 97-121

26 Bullock, T. H. and Northcutt, R. G., A new electroreceptive teleost: Xenomystus nigri (Osteoglossiformes: Notopteridae), J. comp. Physiol., 148 (1982) 345-352.

27 Bullock, T. H., Northcutt, R. G. and Bodznick, D. A. Evolution of electroreception, Trends Neurosci., 5 (1982) 50-53.

28 Bullock, T. H., Hagiwara, S., Kusano, K. and Negishi, $\mathrm{K}$., Evidence for a category of electroreceptors in the lateral line of gymnotid fishes, Science, 134 (1961) 1426-1427.

29 Carr, C., Maler, L., Heiligenberg, W. and Sas, E., Laminar organization of the afferent and efferent systems of the torus semicircularis of Gymnotiform fish: morphological substrates for parallel processing in the electrosensory system, J. comp. Neurol., 203 (1981) 649-670.

30 Clusin, W. T. and Bennett, M. V. L., The oscillatory responses of skate electroreceptors to small voltage stimuli, J. gen. Physiol., 73 (1979) 685-702.

31 Coggi, A., Le ampolle di Lorenzini nei Gimnofioni, Monit. zool. ital., 16 (1905) 49-56.

32 Dahlgren, U., The life history of the fish Astroscopus (the 'Stargazer'), Sci. Mon. NY, 24 (1927) 348-365.

33 Dijkgraaf, S. and Kalmijn, A. J., Verhaltungsversuche zur Funktion der Lorenzinischen Ampullen, Naturwissenschaften, 49 (1962) 400.

34 Dijkgraaf, S. and Kalmijn, A. J., Untersuchungen über die Funktion der Lorenzinischen Ampullen an Haifisch Z. vgl. Physiol., 47 (1963) 438-456.

35 Enger, P. S., Kristensen, L. and Sand, O., The perception of weak electric D.C. currents by the europcan ccl ( $A n$ guilla anguilla), Comp. Biochem. Physiol. A., 54 (1976) 101-103.

36 Escher. K., Das Verhalten der Seitenorgane der Wirbeltiere und ihrer Nerven beim Übergang zum Landleben, Acta zool. Stockholm, 6 (1925) 307-414.

37 Fessard, A. and Szabo, T., Mise en evidence d'un recepteur sensible a l'electricité dans la peau d'un mormyre, $C R$ Acad. Sci., 253 (1961) 1859-1860.

38 Fessard, A. and Szabo, T., Physiology of receptors. II. Peripheral mechanisms of electroreceptors in teleosts. In A Fessard (Ed.), Handbook of Sensory Physiology III/3,

\footnotetext{
* The citations listed are not exhaustive; a more complete bibliography is available in ref. 21
} 
Springer, New York, 1974, pp. 64-95.

39 Fields, R. D. and Lange, G. D., Electroreception in the ratfish (Hydrolagus colliei), Science, 207 (1980) 547-548.

40 Fritzsch, B., Electroreceptors and direction specific arrangement in the lateral line system of salamanders, $Z$. Naturforsch., 36C (1981) 493-495.

41 Fritzsch, B., The pattern of lateral line afferents in Urodeles. Horseradish peroxidase study, Cell Tissue Res., 218 (1981) 581-594.

42 Fıitzsch, B., Claas, B. and Münz, II., Evolution of electroreception, Trends Neurosci., 5 (1982) 144.

43 Fritzsch, B. and Wahnschaffe. U., The electroreceptive ampullary organs of urodeles. A comparative light microscopic and electron microscopic study, in press.

44 Green. J. D., A simple microelectrode for recording from the central nervous system, Nature (Lond.), 182 (1958) 962.

45 Greenwood, P. H., Interrelationships of osteoglossomorphs, Zool. J. Linn. Soc., 53 Suppl. 1, (1973) 307-332.

46 Hagiwara, S. and Morita, H., Coding mechanisms of electroreceptor fibers in some electric fish, $J$. Neurophysiol., 26 (1963) 551-567.

47 Hagiwara, S., Kusano, K. and Negishi, K., Physiological properties of electroreceptors of some gymnotids, J. Neurophysiol., 25 (1962) 430-449.

48 Heiligenberg, W. Principles of electrolocation and jamming avoidance in electric fish. A neuroethological ap. proach. In V. Braitenberg (Ed.), Studies of Brain Function, Springer, New York, 1977, pp. 1-85.

49 Heiligenberg, $W$., The jamming avoidance response in the weakly electric fish Eigenmannia. A behavior controlled by distributed evaluation of electroreceptive afferences, Naturwissenschaften, 67 (1980) 499-507.

50 Heiligenberg, W. and Bastian, J., The control of Eigenmannia's pacemaker by distributed evaluation of electroreceptive afferences, J. comp. Physiol., 136 (1980) 113-133.

51 Heiligenberg. W. and Dye, J., Labelling of electroreceptive afferents in a gymnotoid fish by intracellular injection of HRP: the mystery of multiple maps, J. comp. Physiol., 148 (1982) 287-296.

52 Heiligenberg, W. and Partridge, B. L.. How electroreceptors encode JAR-eliciting stimulus regimes: reading trajectories in a phase-amplitude plane, J. comp. Physiol., 142 (1981) 295-308.

53 Hetherington. T. E. and Wake, M. H., The lateral line system in larval Ichthyophis (Amphibia: Gymnophiona), Zoomorphology, 93 (1979) 209-225.

54 Himstedt. W.. Kopp, J. and Schmidt, W., Electroreception guides feeding behavior in amphibians, Naturwissenschaften, 69 (1982) 552.

55 Johnston, J. B., The brain of Acipenser, Zool. Jahrb. Anat. Ontogenie, 15 (1901) 59-260.

56 Johnston. J. B.. The brain of Petromyzon, J. comp. Neurol., 12 (1902) 1-106.

57 Jørgensen, J. M. . Flock. A and Wersall, J., The Lorenzinian ampullae of Polyodon spathula, Z. Zellforsch., 130 (1972) 362-377.

58 Kalmijn. A. J., Electro-perception in sharks and rats, $\mathrm{Na}$ ture (Lond.), 212 (1966) 1232-1233.

$59 \mathrm{Kalmijn}, \mathrm{A}$. J., The electric sense of sharks and rays, $J$. exp. Biol., 55 (1971) 371-383

$60 \mathrm{Kalmijn}$. A. J., The detection of electric fields from inanimate and animate sources other than electric organs. In
A. Fessard (Ed.), Handbook of Sensory Physiology III/3, Springer, New York, 1974, pp. 147-200.

61 Kalmijn, A. J., Kolba, C. A. and Kalmijn, V., Orientation of catfish (Ictalurus nebulosus) in strictly uniform electric fields: I. Sensitivity of response, Biol. Bull., 151 (1976) 415 (abstr.).

62 Kalmijn, A. J., Kolba, C. A. and Kalmijn, V., Orientation of catfish (Ictalurus nebulosus) in strictly uniform electric fields. II. Spatial discrimination, Biol. Bull., 151 (1976) 415-416 (abstr.),

63 Knudsen, E. I., Midbrain responses to electroreceptive input in catfish, J. comp. Physiol., 106 (1976) 51-67.

64 Knudsen, E. I., Midbrain units in catfish: response properties to electroreceptive input, J. comp. Physiol., 109 (1976) 315-335.

65 Knudsen, E. I., Distinct auditory and lateral line nuclei in the midbrain of catfishes, J. comp. Neurol., 173 (1977) $417-432$.

66 Knudsen, E. I., Functional organization in electroreceptive midbrain of the catfish, J. Neurophysiol., 41 (1978) 350-364.

67 Larsell, O., The Comparative Anatomy and Histology of the Cerebellum from Myxinoids through Birds, University of Minn. Press, Minneapolis, 1967.

68 Lissmann, H. W., On the function and evolution of electric organs in fish, J. exp. Biol., 35 (1958) 156-191.

69 Lissmann, H. W. and Machin, K. E., The mechanism of object location in Gymnarchus niloticus and similar fish, $J$. exp. Biol., 35 (1958) 451-486.

70 Mago-Leccia, F. M., Los peces de la familia Sternopygidae de Venezuela, Acta Cient. Venez., 29 (1978) Suppl. 1, pp. 5-89.

71 Machin, K. E. and Lissmann, H. W., The mode of operation of the electric receptors in Gymnarchus niloticus, $J$. exp. Biol., 37 (1960) 801-811.

72 Maler, L., The posterior lateral line lobe of a mormyrid fish - a Golgi study, J. comp. Neurol., 152 (1973) 281-299.

73 Maler, L., The acousticolateral area of bony fishes and its cerebellar relations, Brain Behav. Evol., 10 (1974) 130-145.

74 Maler, L., The posterior lateral line lobe of certain gymnotoid fish: Quantitative light microscopy, J. comp. Neurol., 183 (1979) 323-364.

75 Maler, L., Karten, H. J. and Bennett, M. V. L., The central connections of the posterior lateral line nerve of Gnathonemus petersii, J. comp. Neurol., 151 (1973) 57-66.

76 Maler, L., Sas, E. K. B. and Rogers, J., The cytology of the posterior lateral line lobe of high frequency weakly electric fish (Gymnotidae): dendritic differentiation and synaptic specificity in a simple cortex, J. comp. Neurol., 195 (1981) 87-140.

77 McCleave, J. D., Rommel, S. A. and Cathcart, C. L., Weak electric and magnetic fields in fish orientation, $A n n$. NY Acad. Sci., 188 (1971) 270-282.

78 McCormick, C. A., Central Projections of the Lateralis and Eighth Nerves in the Bowfin, Amia calva, Ph. D. Thesis. Univ. of Michigan, Ann Arbor, MI, 1978.

79 McCormick, C. A., Central projections of the lateral line and eighth nerves in the bowfin, Amia calva, J. comp. Neurol., 197 (1981) 1-15.

80 McCormick, C. A., Comparative neuroanatomy of the octavolateralis area of fishes. In W. N. Tavolga, A. N. Popper and R. R. Fay (Eds.), Hearing and Sound Commu- 
nication in Fishes, Springer-Verlag, New York, 1981, pp. 375-382.

81 McCormick, C. A., The organization of the octavolateralis area in actinopterygian fishes: a new interpretation, $J$. Morphol., 171 (1982) 159-181.

82 McCready, P. J. and Boord, R. L., The topography of the superficial roots and ganglia of the anterior lateral line nerve of the smooth dogfish, Mustelus canis, J. Morphol., 150 (1976) 527-538.

83 Mikhailenko, N. A., Biological significance and dynamics of electrical discharges in weak electrical fishes of the Black Sea, Zool. Zh., 50 (1971) 1347-1352 (in Russian).

84 Mikhailenko, N. A., Organ of sound formation and electrogeneration in the Black Sea stargazer (Uranoscopidae), Zool. Zh., 52 (1973) 1353-1359 (in Russian).

85 Münz. H. . Claas, B. and Fritzsch, B., Electrophysiological evidence of electroreception in the axolotl Siredon mexicanum, Neurosci. Lett., 28 (1982) 107-111.

86 Murray, R. W., Electrical sensitivity of the ampullae of Lorenzini, Nature (Lond.), 187 (1960) 957.

87 Murray. R. W.. The response of the ampullae of Lorenzini of elasmobranchs to electrical stimulation, J. exp. Biol., 39 (1962) 119-128

88 Murray, R. W. The ampullae of Lorenzini. In A. Fessard (Ed.), Handbook of Sensory Physiology III/3, Springer, New York, 1974, pp. 125-146.

89 Nelson, J. S. Fishes of the World, Wiley, New York.

90 New. J. G., Central Projections of the Lateralis Nerves in the Shovelnose Sturgeon. Scaphirhynchus platorynchus. Master's Thesis, University of Michigan, Ann Arbor, 1981.

91 Northcutt, R. G., Anatomical evidence of electroreception in the coelacanth (Latimeria chalumnae), $\mathrm{Zbl}$. Vet. Med. Reihe C, 9 (1980) 289-295.

92 Northcutt, R. G., Audition and the central nervous system of fishes. In W. N. Tavolga, A. N. Popper and R. R. Fay (Eds.). Hearing and Sound Communication in Fishes, Springer, New York, 1981, pp. 331-355.

93 Obara, S. and Bennett, M. V. L., Mode of operation of ampullae of Lorenzini of the skate, Raja J. gen. Physiol., 60 (1972) 534-557.

94 Olson, E. C., Vertebrate Paleontology, Wiley, New York, 1971.

95 Opdam. P. and Nieuwenhuys, R., Topological analysis of the brain stem of the Axolotl Ambystoma mexicanum, $J$. comp. Neurol., 165 (1976) 285-306.

96 Partridge, B. L. Heiligenberg, W. and Matsubara, J., The ncural basis of a behavioral filter: no grandmother cells in sight, $J$. comp. Physiol., 145 (1981) 153-168.

97 Pearson. R. G., The acoustico-lateral centers and the cerebellum, with fiber connections, of fishes, J. comp. Neurol., 65 (1936) 201-294

98 Platt, C. J.. Bullock. T. H., Czéh. G., Kovačević, N. Konjević, Dj. and Gojković, M., Comparison of electroreceptor, mechanoreceptor, and optic evoked potentials in the brain of some rays and sharks. J. comp. Physiol., 95 (1974) 323-355.

99 Richardson, N. E., McCleave, J. D. and Albert, E. H., Effect of extrcmely low frequency clectric and magnetic fields on locomotor activity rhythms of Atlantic salmon
(Salmo salar) and American eels (Anguilla rostrata), Environ. Pollut., 10 (1976) 65-76.

100 Rommel, S. A. and McCleave, J. D., Oceanic electric fields: perception by American eels?, Science, 176 (1972) 1233-1235.

101 Rommel, S. A. and McCleave, J. D. Sensitivity of American eels (Anguilla rostrata) and Atlantic salmon (Salmo salar) to weak electric and magnetic fields, J. Fish. Res. Board Can., 30 (1973) 657-663.

102 Roth, A., Electroreceptors in Brachioterygii and Dipnoi, Naturwissenschaften, 60 (1973) 106.

103 Rubinson, K., The central distribution of VIII nerve afferents in larval Petromyzon marinus, Brain Behav. Evol., 10 (1974) 121-129.

104 Scheich, H. and Bullock, T. H., The detection of electric fields from electric organs. In A. Fessard (Ed.), Hand book of Sensory Physiology, III/3, Springer, New York, 1974, pp. 201-256

105 Smeets, W. J. A. J. and Nieuwenhuys, R., Topological analysis of the brainstem of the sharks Squalus acanthias and Scyliorhinus canicula, J. comp. Neurol., 165 (1976) 333-368.

106 Stendell, W., Die Faseranatomie des Mormyriden Gehirns, Abh. Senckenb naturforsch. Ges., 36 (1914) 3-40.

107 Suga, N., Coding in tuberous and ampullary organs of a gymnotid electric fish, J. comp. Neurol., 131 (1967) 437-451

108 Suga, N., Electrosensitivity of specialized and ordinary lateral line organs of the electric fish, Gymnotus carapo. In P. Cahn (Ed.), Lateral Line Detectors, Indiana Univ. Press, Bloomington, IN, 1967, pp. 395-409.

109 Szabo, T., Sense organs of the lateral line system in some electric fish of the Gymnotidae, Mormyridae and Gymnarchidae, J. Morph., 117 (1965) 229-250.

110 Szabo, T., Anatomy of the specialized lateral line organs of electroreception. In A. Fessard (Ed.), Handbook of Sensory Physialogy, III/3, Springer, New York, 1974, pp. $13-58$.

111 Szabo, T., Central processing of messages from tuberous electroreceptors in teleosts. In A. Fessard (Ed.), Handbook of Sensory Physiology, III/3, Springer, New York, 1974, pp. 95-124.

112 Teeter, J. H., Szamier, R. B. and Bennett, M. V. L., Ampullary electroreceptors in the sturgeon Scaphirhynchus platorynchus (Rafinesque), J. comp. Physiol., 138 (1980) 213-223

113 Tong, S.-L., The nucleus praeeminentialis: an electro-and mechanoreceptive center in the brainstem of catfish, $J$. comp. Physiol., 145 (1982) 299-309.

114 Tong, S.-L. and Bullock, T. H., Electroreceptive representation and its dynamics in the cerebellum of the catfish, Ictalurus nebulosus (Ictaluridae, Siluriformes), $J$. comp. Physiol., 145 (1982) 289-298.

115 Tong, S.-L. and Finger, T. E., Central organization of the electrosensory lateral line system in bullhead catfish Ictalurus nebulosus, J. comp. Neurol., in press.

116 Viancour, T. A., Peripheral electrosense physiology: a review of recent findings, J. Physiol. (Paris), 75 (1979) 321- 333 . 